\title{
NMR Spectroscopic Study of Side Reactions in Anionic Polymerization of Acrylonitrile
}

\author{
Hirofumi Ono, Kunio Hisatani, and Kenji Kamide* \\ Fundamental Research Laboratory of Fibers and Fiber-Forming Polymers, \\ Asahi Chemical Industry Co., Ltd., Takatsuki, Osaka 569, Japan
}

(Received August 6, 1992)

\begin{abstract}
An NMR study was conducted on the mechanisms of side reactions in anionic polymerization of acrylonitrile (AN) with di- $n$-hexylmagnesium as an initiator in mixed-xylene at $25^{\circ} \mathrm{C}$. In the initiation step the metalation of AN monomer leads to deactivation of the initiator. In the propagation stage both chain transfer to an $\alpha$-proton in propagating chain and metalation of monomer proceed in parallel with addition reaction of the AN monomer to the propagating chain. The former two reactions result in 1) formation of branching structures and 2) deactivation of active site, respectively. Some new NMR peaks resulting from above side reactions, which did not appear in ${ }^{13} \mathrm{C}$ NMR spectra of radically prepared PAN, were assigned. According to the assignments in this work, the number-average molecular weight, $M_{n}(330-5600)$ and branching density, which means the number of branching per 100 repeating units, were estimated for acetone-soluble or acetone-insoluble products.

KEY WORDS Anionic Polymerization / Acrylonitrile / Side Reaction / NMR / Two-Dimensional NMR / Metalation / Intramolecular Chain Transfer / Branching Structure /
\end{abstract}

Acrylonitrile (AN) can be polymerized to give polyacrylonitrile (PAN) not only by radical initiators but also by anionic initiators. ${ }^{1}$ In general, the advantages of anionic polymerization are easiness of controling the molecular weight distribution by means of the "living" nature of its propagating chain and route that they provide for the syntheses of new functional polymers such as block copolymer and star-like polymer. Anionic polymerization also affords a possible route for the production of stereoregular polymers by nature of counter ion structure forming in its propagating end group.

In the case of polymerization of monomer with polar group such as $\mathrm{AN}$, side reactions based on the attack of propagating carbanion on the polar group result in some loss of the "living" nature of the system. ${ }^{2,3}$ In fact, the "living" nature has never been found in the anionic polymerization of $\mathrm{AN}$ because of the direct attack of the propagating chain on the cyano group ${ }^{4}$ or an attack against electrophilic $\alpha$-proton activated by the cyano group. ${ }^{5}$ In order to obtain high molecular weight PAN (ca. $5 \times 10^{5}$ ) with high yield, it is necessary to polymerize under strictly limited conditions, for example, at very low temperature. ${ }^{5}$ This may be a major reason why the anionic polymerization of $\mathrm{AN}$ has not been utilized commercially, though only short time is needed for completion of the polymerization owing to low activation energy.

As mentioned above, side reactions cannot be ignored in anionic polymerization of AN. Many authors have proposed mechanisms for the polymerization ${ }^{4-8}$ : Kawabata and Tsuruta $^{6}$ indicated that the metalation reaction of monomer occurs at an early stage with butyllithium as an initiator. Ottolenghi and

* To whom all correspondences should be addressed. 
Zilkha $^{7}$ suggested that an attack by the propagating carbanion on neighbor cyano group leads to the formation of continuous cyclic imine structure. Erusallimsky et $a l^{4}$ proposed the cyclic terminal structure formed by intramolecular attack of carbanion against cyano group in penpenultimate monomer unit. Galin et al. ${ }^{8}$ and Malsch et al. ${ }^{9}$ indicated from the data of hydrodynamic property that branches exist in PAN chain when prepared in anionic polymerization system. To explain the mechanism of formation of these structures, Malsch et al. ${ }^{9}$ proposed intramolecular and intermolecular chain transfer reactions to polymer. Joh ${ }^{10}$ indicated that the cyclic imine structure suggested by Ottolenghi and Zilkha ${ }^{7}$ became an acid amide by hydrolysis reaction through the addition of hydrochloric acid as a terminator in case of the polymerization of methacrylonitrile. In addition to these side reactions, some decomposition reactions of PAN chain ${ }^{5,11,12}$ were also pointed out to occur during the polymerization.

In recent years, remarkable progress in NMR techniques has made it possible to analyze to "hetero-structure" of polymer chains caused by initiation or some side reactions, for example, initiator fragment incrorporated into a polymer chain, branched structure, head to head or tail to tail structure. $^{13}$ However, as far as the anionic polymerization of $\mathrm{AN}$ is concerned, the NMR spectroscopic technique has rarely been employed to examine the side reaction mechanisms proposed by the above authors. The only exception is the work of Sheller et al., ${ }^{14}$ in which, from an assignment of ${ }^{13} \mathrm{C} N M R$ spectrum with rather poor resolution power (because they used $25 \mathrm{MHz}$ machine for ${ }^{13} \mathrm{C}$ ), they assumed the branched structure without detailed theoretical background of assignment of each peak. For this reason, we cannot estimate the degrees of side reactions relative to the propagation reaction.

In this article, we studied by NMR measurements side reactions which suppress the formation of high molecular weight polymers or damage "living" nature of the propagating chain, and determined the relative frequencies of the side reactions to that of the main reaction (propagation reaction). For this purpose, AN-oligomer/polymer mixtures having hetero-structure were synthesized under rather specific conditions which favor side reactions.

\section{EXPERIMENTAL}

\section{Materials}

AN and methacrylonitrile (MAN) supplied by Wako Pure Chemical Industries, Ltd. (Osaka, Japan) were purified by fractional distillation and dried over calcium dihydride. Commercially available mixed xylene and dimethoxyethane (DME), supplied by Wako Pure Chemical Industries, Ltd., were used after storing over molecular sieves (13X) for at least one week. Di- $n$-hexylmagnesium was supplied in the form of $n$-heptane solution by TosoAkzo Co., Ltd. (Tokyo, Japan). Sodium 2phenoxyethoxide was synthesized by dropping 2-phenoxyethanol (supplied by Kishida Chemical Co., Ltd., Osaka, Japan) into dispersed sodium in mixed xylene at $110^{\circ} \mathrm{C}$.

\section{Polymerization}

The polymerizations of $\mathrm{AN}$ and MAN were carried out in $200 \mathrm{ml}, 500 \mathrm{ml}$, or $1000 \mathrm{ml}$ three-necked flasks under $99.999 \%$ nitrogen. $n$-Heptane solutions containing the given amounts of initiator shown in Table I were added to each solvent in the flask at room temperature. In each case the flask was heated or cooled to the given polymerization temperature $T_{\mathrm{p}}$ and kept at $T_{\mathrm{p}}$ for $10 \mathrm{~min}$. The monomer $(10 \mathrm{ml})$ was then added through a syringe to the initiator solution. The polymerization was stopped after $1 \mathrm{~h}$ by adding 20 $\mathrm{ml}$ of methanol containing hydrochloric acid (ca. $2 \mathrm{ml}$ of $2 \mathrm{~N}$ aqueous solution). For $\mathrm{AN}$ polymerizations, the transparent solution of initiator turned to a dark yellowish slurry by 
Side Reactions in Anionic Polymerization of AN

Table I. Polymerization of AN or MAN with an anionic initiator in mixed-xyrene or dimethoxyethane

\begin{tabular}{|c|c|c|c|c|c|c|c|}
\hline \multirow{3}{*}{ Run No. } & \multicolumn{4}{|c|}{ Polymerization conditions } & & \multirow{3}{*}{$\begin{array}{l}\text { Sample } \\
\text { No. }\end{array}$} & \multirow{3}{*}{$\frac{\text { Conversion }}{\%}$} \\
\hline & \multirow{2}{*}{ Monomer $^{\mathrm{a}}$} & Initiator & Solvent & Temperature & & & \\
\hline & & $(\mathrm{mmol})$ & $(\mathrm{ml})$ & ${ }^{\circ} \mathrm{C}$ & & & \\
\hline AM-1 & $\mathrm{AN}$ & $\begin{array}{l}(n \text {-hexyl })_{2} \mathrm{Mg} \\
(2.54)\end{array}$ & $\begin{array}{l}\text { Xylene }{ }^{b} \\
(200)\end{array}$ & 25 & $\begin{array}{l}\text { Whole products } \\
\text { Acetone-insoluble } \\
\text { Acetone-soluble }\end{array}$ & $\begin{array}{l}\text { AM-1A } \\
\text { AM-1B } \\
\text { AM-1C }\end{array}$ & $\begin{array}{l}30.2 \\
15.9 \\
14.3\end{array}$ \\
\hline $\mathrm{AM}-2$ & $\mathrm{AN}$ & $\begin{array}{r}(n \text {-hexyl })_{2} \mathrm{Mg} \\
(2.54)\end{array}$ & $\begin{array}{l}\text { Xylene }^{\mathrm{b}} \\
(100)\end{array}$ & 120 & $\begin{array}{l}\text { Acetone-insoluble } \\
\text { Acetone-soluble }\end{array}$ & $\begin{array}{l}A M-2 B \\
A M-2 C\end{array}$ & $\begin{array}{l}54.5 \\
14.7\end{array}$ \\
\hline AM-3 & $A N$ & $\begin{array}{l}(n \text {-hexyl })_{2} \mathrm{Mg} \\
(7.62)\end{array}$ & $\begin{array}{l}\text { Xylene }^{\mathrm{b}} \\
(600)\end{array}$ & 120 & $\begin{array}{l}\text { Acetone-insoluble } \\
\text { Acetone-soluble }\end{array}$ & $\begin{array}{l}\text { AM-3B } \\
\text { AM-3C }\end{array}$ & $\begin{array}{l}46.6 \\
18.9\end{array}$ \\
\hline AM-4 & $\mathrm{AN}$ & $\begin{array}{r}\mathrm{PhOCH}_{2} \mathrm{CH}_{2} \mathrm{ONa} \\
(2.00)\end{array}$ & $\begin{array}{l}\mathrm{DME}^{\mathrm{c}} \\
\quad(50)\end{array}$ & -50 & Acetone-insoluble & AM-4B & 20.3 \\
\hline AX-1 & MAN & $\begin{array}{l}(n \text {-hexyl })_{2} \mathrm{Mg} \\
(2.54)\end{array}$ & $\begin{array}{l}\text { Xylene }^{\mathrm{b}} \\
(200)\end{array}$ & 25 & Whole polymer & AX-1A & 53.8 \\
\hline
\end{tabular}

a Monomer $10 \mathrm{ml}(0.152 \mathrm{mmol})$.

b Mixture of $o-, m$-, and $p$-xylene.

c Dimethoxyethane.

the addition of monomer. Immediately after introducing the terminator, the slurry color became light yellow. In the case of the polymerization of MAN, slurry color was dark brown and turned almost white simultaneously with the addition of terminator. Other polymerization conditions are summerized in Table I.

The slurry obtained was filtered off through sintered glass (grade G3), washed with boiling water several times, and dried. The white or yellow powders obtained were reduced to fine powders in an agate mortar. A mixture of the powder and acetone $(50 \mathrm{ml}$ against $1 \mathrm{~g}$ of powder) was refluxed with stirring for $6 \mathrm{~h}$, filtered, and dried to yield an "acetone insoluble fraction." The acetone soluble compound was separated from the filtrate by vaccum evaporation and dried to yield an "acetone soluble fraction."

\section{NMR Measurements}

NMR spectra were measured for samples in Table I as $5-10 \%$ solutions in dimethyl sulfoxide (DMSO)- $d_{6}$ at $80^{\circ} \mathrm{C}$ on a JEOL
GSX-400 spectrometer $\left({ }^{1} \mathrm{H}\right.$ frequency of $399.78 \mathrm{MHz}$ or ${ }^{13} \mathrm{C}$ frequency of $100.54 \mathrm{MHz}$ ). Tetramethylsilane (TMS; 0 ppm) was used as an internal reference and commercial grade glutaronitrile was used as a model compound to assign the chemical shifts of PAN samples prepared by anionic polymerization.

${ }^{1} \mathrm{H}$ NMR measurements were carried out under the following conditions: Observation range, $8000 \mathrm{~Hz}$; pulse width, $8.0 \mu \mathrm{s}\left(45^{\circ}\right.$ pulse $)$; delay time, $2.635 \mathrm{~s}$; data sampling time, $1.365 \mathrm{~s}$; data point, $16 \mathrm{~K}$.

${ }^{13} \mathrm{C}$ NMR measurements were carried out using gated decoupling mode under the following conditios: Observation range, $25000 \mathrm{~Hz}$; pulse width, $12.0 \mu \mathrm{s}\left(90^{\circ}\right.$ pulse); delay time, $10-20 \mathrm{~s}$; data sampling time, $0.655 \mathrm{~s}$; data point, $32 \mathrm{~K}$; number of pulse, over than 4000 .

J-Resolved two-dimensional (2D-) ${ }^{13} \mathrm{C}$ NMR spectra were measured under the following conditions: Observation range for ${ }^{13} \mathrm{C}$-axis, $3200 \mathrm{~Hz}$; data points for ${ }^{13} \mathrm{C}$-axis, 2048; observation range for J-axis, $400 \mathrm{~Hz}$; sampling times along $\mathrm{J}$-axis, 128 ; data points for J-axis, zero-filled to 256 points. 
${ }^{13} \mathrm{C}-{ }^{1} \mathrm{H}$ shift correlation $\left({ }^{13} \mathrm{C}-{ }^{1} \mathrm{H}\right.$ COSY $)$ 2D-NMR spectra were measured under the following conditions: Observation range for ${ }^{13} \mathrm{C}$-axis, $40000 \mathrm{~Hz}$; data points for ${ }^{13} \mathrm{C}$-axis, 2048; observation range for ${ }^{1} \mathrm{H}$-axis, $1900 \mathrm{~Hz}$; sampling times along ${ }^{1} \mathrm{H}$-axis, 256; data points for ${ }^{1} \mathrm{H}$-axis, zero-filled to 512 points.

${ }^{1} \mathrm{H}-{ }^{1} \mathrm{H}$ shift correlation $\left({ }^{1} \mathrm{H}-{ }^{1} \mathrm{H}\right.$ COSY $)$ 2D-NMR measurements were performed under the following conditions: Observation range, $1800 \mathrm{~Hz}$; data points, 2048; sampling times for column-axis, 256; data points for column-axis, zero-filled to 512 points. Pulse widths for pulse sequence in each twodimensional measurement were the same value as those used in ${ }^{1} \mathrm{H}$ - or ${ }^{13} \mathrm{C}$-one-dimensional NMR measurements. Here, in order to improve resolution, free induction decays were multiplied by pseudoecho window function prior to Fourier transformation.

\section{Molecular Orbital Calculations}

Molecular orbital calculations with respect to electron density and atomic bond population were carried out using the GAUSSIAN88 program $^{15}$ based on the STO-3G basis set. As far as geometric parameters of AN, MAN, 2-cyanopropane, and 2,2-dimethylpropanenitrile were concenrned, literature data ${ }^{16} \mathrm{ob}$ tained by electron diffraction and microwave measurements for the compound itself (AN) or those with the similar structures shown in parentheses in the following list (see Figure 2 for each atom number) were used:

AN, (Length is abbreviated to $L$ in below)

$$
\begin{aligned}
& L_{\mathrm{C}-\mathrm{H}}=1.114 \AA, L_{\mathrm{C} 1-\mathrm{C} 2}=1.343 \AA, \\
& L_{\mathrm{C} 2-\mathrm{C} 3}=1.438 \AA, L_{\mathrm{C} 3-\mathrm{N}}=1.167 \AA, \\
& \angle \mathrm{C}_{1} \mathrm{C}_{2} \mathrm{C}_{3}=121.7^{\circ}, \angle \mathrm{C}_{2} \mathrm{C}_{3} \mathrm{~N}=180^{\circ}
\end{aligned}
$$

(referred from AN data: Other all $s p^{2}$ bond angles for carbon are $120^{\circ}$ )

$$
\begin{aligned}
& \text { MAN, } \\
& L_{\mathrm{C} 1-\mathrm{H}}=1.114 \AA(\mathrm{AN}), \\
& L_{\mathrm{C} 4-\mathrm{H}}=1.117 \AA \text { (propene), }
\end{aligned}
$$

$$
\begin{aligned}
& L_{\mathrm{C} 1-\mathrm{C} 2}=1.343 \AA(\mathrm{AN}), \\
& L_{\mathrm{C} 2-\mathrm{C} 3}=1.438 \AA(\mathrm{AN}), \\
& L_{\mathrm{C} 2-\mathrm{C} 4}=1.508 \AA \text { (propene), } \\
& L_{\mathrm{C} 3-\mathrm{N}}=1.167 \AA(\mathrm{AN}), \\
& \angle \mathrm{C}_{1} \mathrm{C}_{2} \mathrm{C}_{3}=121.7^{\circ}(\mathrm{AN}), \\
& \angle \mathrm{C}_{2} \mathrm{C}_{4} \mathrm{H}=110.7^{\circ} \text { (propene), } \\
& \angle \mathrm{C}_{2} \mathrm{C}_{3} \mathrm{~N}=180^{\circ}(\mathrm{AN})
\end{aligned}
$$

(All other $s p^{2}$ bond angles for carbon are equal at $120^{\circ}$ )

2-Cyanopropane,

$$
\begin{aligned}
& L_{\mathrm{C} 1-\mathrm{H}}=1.107 \AA \text { (isobutane), } \\
& L_{\mathrm{C} 2-\mathrm{H}}=1.113 \AA \text { (acetonitrile), } \\
& L_{\mathrm{C} 1-\mathrm{C} 2}=1.535 \AA \text { (isobutane), } \\
& L_{\mathrm{C} 2-\mathrm{C} 4}=1.468 \AA \text { (acetonitrile), } \\
& L_{\mathrm{C} 4-\mathrm{N}}=1.159 \AA \text { (acetonitrile), } \\
& \angle \mathrm{C}_{1} \mathrm{C}_{2} \mathrm{C}_{3}=\angle \mathrm{C}_{1} \mathrm{C}_{2} \mathrm{C}_{4}=\angle \mathrm{C}_{4} \mathrm{C}_{2} \mathrm{H}=109.7^{\circ}
\end{aligned}
$$

(acetonitrile),

$$
\begin{aligned}
& \angle \mathrm{C}_{2} \mathrm{C}_{1} \mathrm{H}=111.4^{\circ} \text { (isobutane), } \\
& \angle \mathrm{C}_{2} \mathrm{C}_{4} \mathrm{~N}=180^{\circ} \text { (acetonitrile) }
\end{aligned}
$$

2,2-Dimethylpropanenitrile,

$$
\begin{aligned}
& L_{\mathrm{C}-\mathrm{H}}=1.107 \AA \text { (isobutane), } \\
& L_{\mathrm{C} 1-\mathrm{C} 2}=1.535 \AA \text { (isobutane), } \\
& L_{\mathrm{C} 2-\mathrm{C} 5}=1.468 \AA \text { (acetonitrile), } \\
& L_{\mathrm{C} 5-\mathrm{N}}=1.159 \AA \text { (acetonitrile), } \\
& \angle \mathrm{C}_{1} \mathrm{C}_{2} \mathrm{C}_{3}=111.4^{\circ} \text { (isobutane), } \\
& \angle \mathrm{C}_{1} \mathrm{C}_{2} \mathrm{C}_{5}=109.7^{\circ} \text { (acetonitrile), } \\
& \angle \mathrm{C}_{2} \mathrm{C}_{5} \mathrm{~N}=180^{\circ} \text { (acetonitrile) }
\end{aligned}
$$

\section{Vapor Pressure Osmometry}

The apparatus was constructed by Kamide et al. $^{17}$ (prototype of Hitachi (now, Corona) 117 model). Number-average molecular weight $M_{n}$ was evaluated from an intercept of the plots of $\Delta T_{s} / c$ vs. $c$ ( $c$, polymer concentration) at $c=0$ using benyl (special grade, molecular weight; 210.23 ) as standard material and acetonitrile as solvent at $40^{\circ} \mathrm{C}$. 
Solution Viscosity and Viscosity-Average Molecular Weight

Solution viscosity of the acetone-solubles and acetone-insolubles in DMSO was measured in a Ubbelohde-type suspension viscometer at $25^{\circ} \mathrm{C}$. Limiting viscosity number $[\eta]$ was evaluated by Huggins plots.

The viscosity-average molecular weight $M_{v}$ was evaluated for these samples from the Mark-Houwink-Sakurada equation,

$$
[\eta]=0.153 M_{w}^{0.60}
$$

established for atactic PAN in DMSO at $25^{\circ} \mathrm{C}$ by Kamide et al. ${ }^{18}$

\section{Gel Permiation Chromatograms (GPC)}

GPC chromatograms were measured using Shodex RISE-61 detector euqipped with two Shodex columns KD-803 (maximum porosi- ty $=7 \times 10^{4}$; fillers: styrene-divinylbenzene copolymer) and KD-80M (maximun porosity $=5 \times 10^{7}$; fillers: styrene-divinyl benzene copolymer) joined in series. The sample was prepared as a $0.1 \%$ solution in $N, N$ dimethylacetoamide (DMAc) containing $0.2 \%$ lithium chloride as an eluent at the rate of $1.0 \mathrm{ml} \mathrm{min}^{-1}$ at $50^{\circ} \mathrm{C}$.

\section{RESULTS AND DISCUSSION}

Polymerization of $A N$ and NMR Analysis of the Polymerization Products

AN oligomers or polymers with heterostructure were preferentially synthesized under polymerization conditions carefully chosen as summarized in Table I. The polymerization products were separated into "acetone-soluble fraction" and "acetone-insoluble fraction" by

(a)

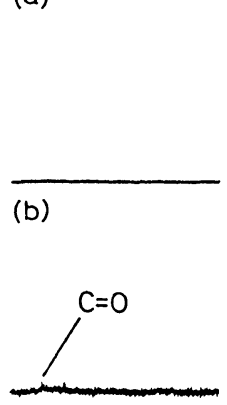

(c)

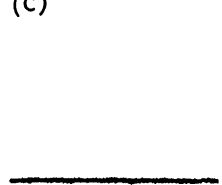

(d)
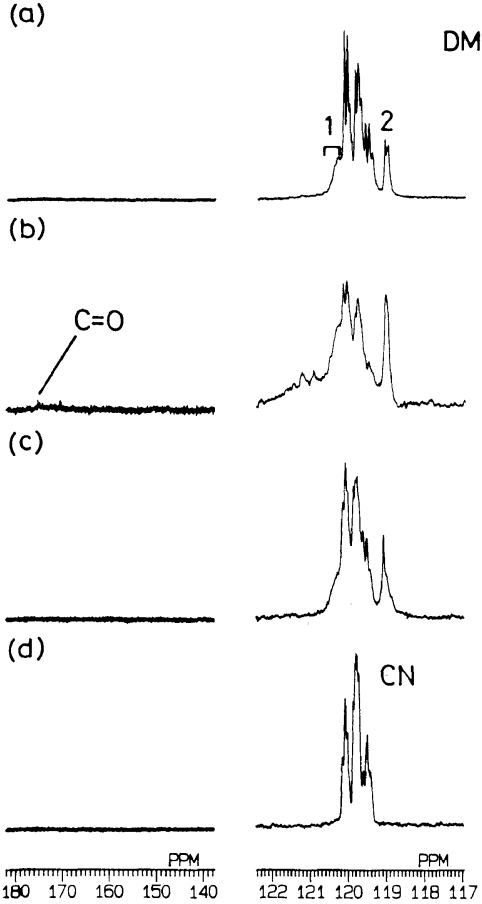
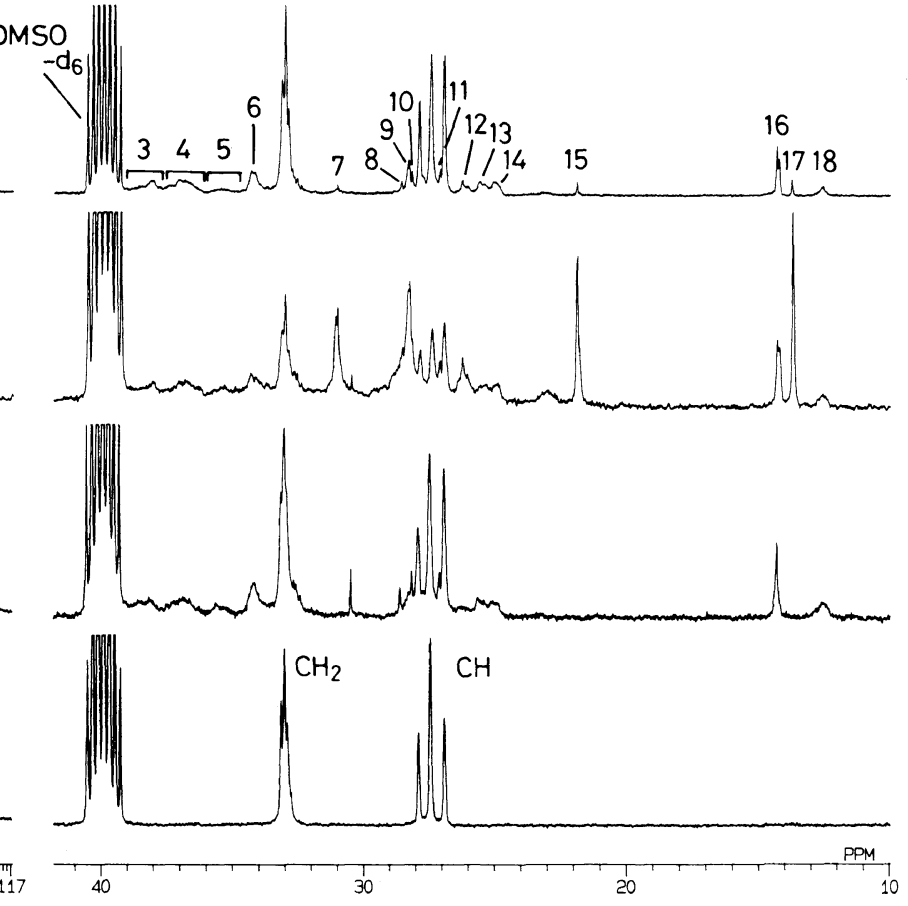

Figure 1. ${ }^{13} \mathrm{C}$ NMR spectra measured at $80^{\circ} \mathrm{C}$ for DMSO- $d_{6}$ solution of (a) the acetone-insolule fraction (sample AM-1B) and (b) the acetone-soluble fraction (sample AM-1C), prepared using di- $n$-hexylmagnesium as an initiator in xylene at $25^{\circ} \mathrm{C}$, (c) the acetone-insoluble fraction (sample AM-4B) initiated by sodium 2-phenoxyethoxide in dimethoxyethane at $-50^{\circ} \mathrm{C}$, and (d) PAN prepared by redox-type initiator in aquaous medium at $55^{\circ} \mathrm{C}$. 
the procedure described in experimental term. The results of polymerization experiments are summarized in columns six, seven, and eight in Table I.

Figure 1(a) and 1(b) show ${ }^{13} \mathrm{C}$ NMR spectra of an acetone-insoluble fraction (sample AM-1B) and an acetone-soluble fraction (sample AM-1C), both in DMSO- $d_{6}$, respectively. Here, the sample AM-1A, from which acetone-insoluble and acetone-soluble fractions were separated, were synthesized in xylene using di- $n$-hexylmagnesium as an initiator at $25^{\circ} \mathrm{C}$ (see Table I). Figure $1(\mathrm{c})$ shows ${ }^{13} \mathrm{C}$ NMR spectrum for an acetone-insoluble fraction (sample AM-4B) synthesized using sodium 2-phenoxyethoxide as an initiator in DME at $-50^{\circ} \mathrm{C}$. In ${ }^{13} \mathrm{C}$ NMR spectra of samples AM-1B and AM-1C some new peaks designated by $1-18$ are found in addition to those from main resonances (corresponding to main chain $\mathrm{CH}, \mathrm{CH}_{2}$, and side chain $\mathrm{CN}$ ) observed in conventional PAN. ${ }^{19}$ Figure 1(d) shows ${ }^{13} \mathrm{C}$ NMR spectrum of PAN prepared by radical polymerization using a redox-type initiator. Peaks $1-18$ were not observed in any PAN samples prepared using a radical initiator ${ }^{19}$ or by $\gamma$-ray irradiation on $\mathrm{AN}$-urea canal complex. ${ }^{20}$ Therefore, these peaks can be considered closely related to initiation and/or side reactions in the polymerization system employed here. Inspection of Figure 1(a) and 1(b) shows that the content of hetero-structure caused by these side reactions is significantly larger in acetone-soluble fraction than in acetone-insoluble fraction.

In Figure 1(c), peaks 7, 9, 15, and 17 are not observed for sample AM-4B. Peak 12 is composed of two components, i.e., sharp component and broad one in Figure 1(a), but the sharp component of peak 12 is diminished in Figure 1(c). This suggests that these five peaks are closely correlated with $n$-hexyl group incorporated into chain by initiation reaction in di- $n$-hexylmagnesium/xylene polymerization system. The fourteen peaks $1-6,8$, $10-14,16$, and 18 observed for sample AM$1 \mathrm{~B}$ are also found for sample AM-4B. We confirmed the existence of all these fourteen peaks in ${ }^{13} \mathrm{C}$ NMR spectra of PAN samples prepared using other anionic polymerization systems including $n$-butyllithium/tetrahydrofuran at $-78^{\circ} \mathrm{C}$ and sodium cyanide/DMF at $0^{\circ} \mathrm{C}$. The fourteen peaks can therefore be considered to be caused by elementary reactions in anionic polymerization other than the initiation or propagation reactions.

\section{Mechanisms of Side Reactions in Anionic Polymerization of $A N$}

Speculation of Side Reactions. In order to give correct assignments for peaks $1-18$, first, we speculate on possible side reactions occurring in the anionic polymerization of AN when di- $n$-hexylmagnesium is used as initiator. Elementary reactions in the initiation step and the propagation step, and decomposition reactions ${ }^{5,11,12}$ are as follows:

\section{Initiation steps}

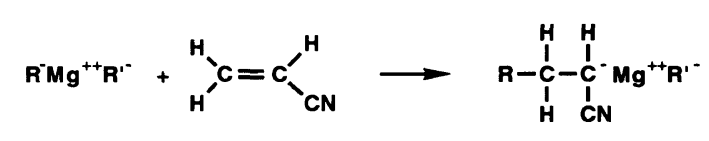

(R; $n-C_{6} H_{13}, R^{\prime} ; n-C_{6} H_{13}$ or propagating chain)

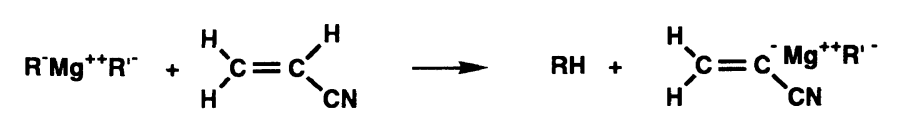


Propagation step

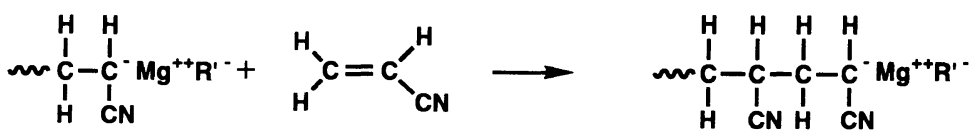

(termination or chain transfer reactions)
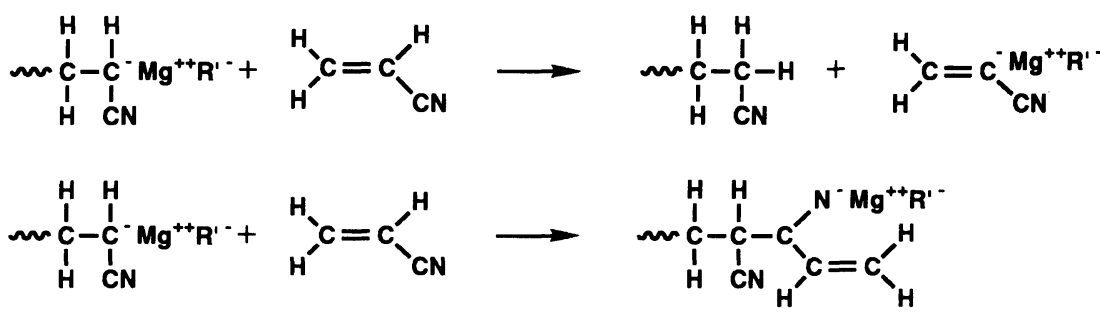

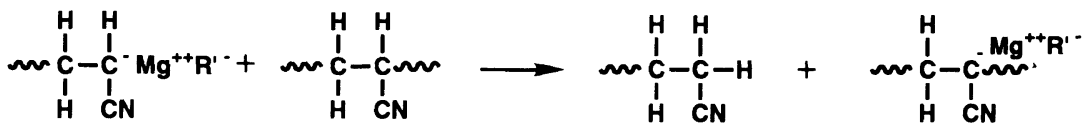

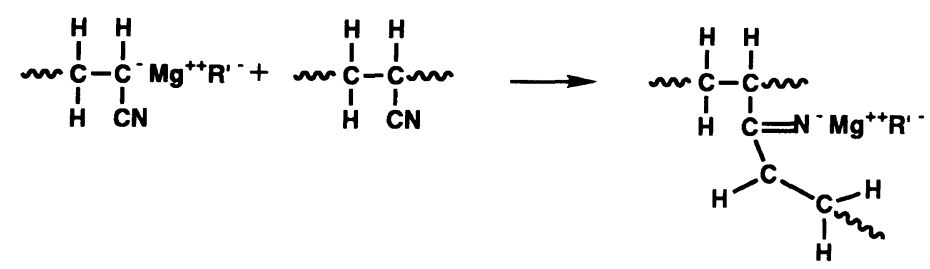

Decomposition reactions

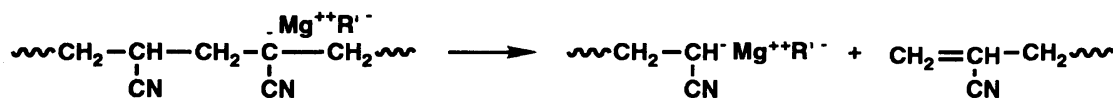

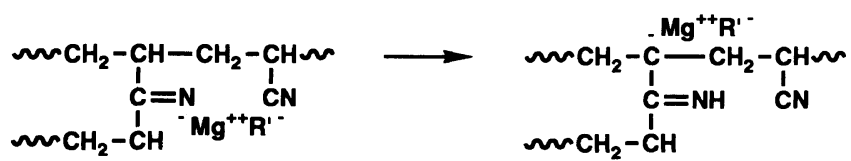
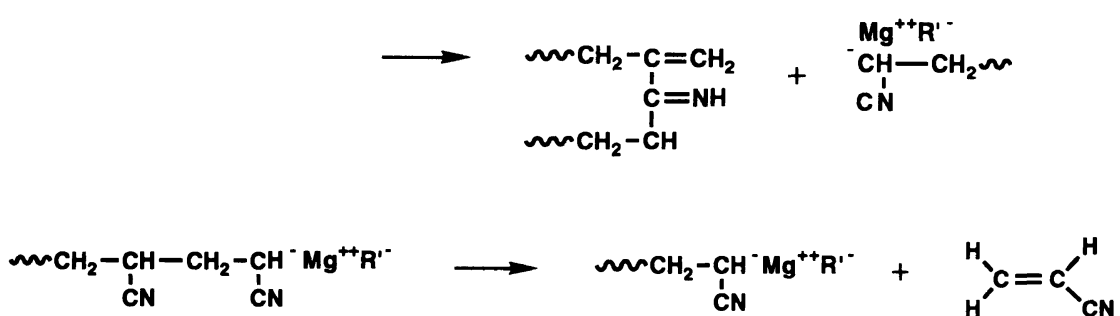

In this paper, we do not discuss the complex structure formed in propagating end group such as ion triplet proposed by Tsvetanov et $a l .^{21}$
Among elementary reactions (a)-(j), reactions (a), (b), (d), (e), (f), (g), (h), and (i) result in hetero-structures in the polymer chain. Reactions (e) and (g) correspond to 


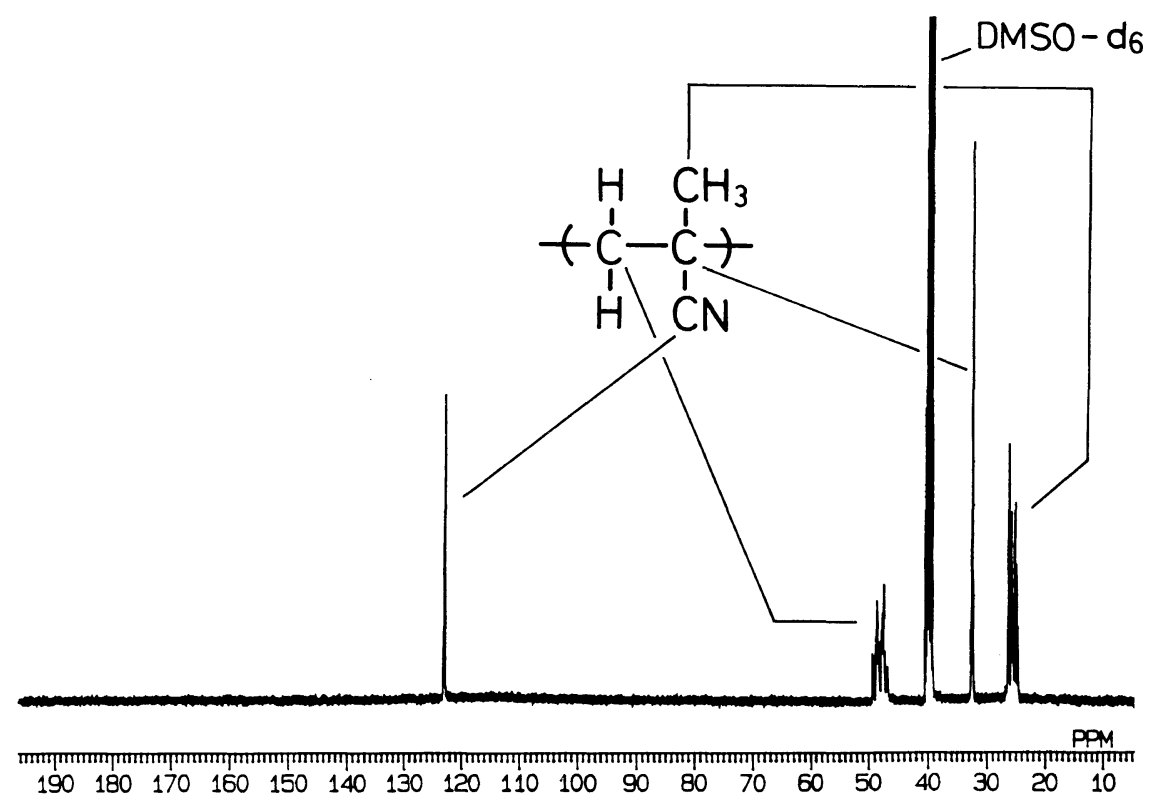

Figure 2. ${ }^{13} \mathrm{C}$ NMR spectrum measured at $80^{\circ} \mathrm{C}$ for DMSO- $d_{6}$ solution of whole product (sample $\mathrm{AX}-1 \mathrm{~A}$ ) obtained by the polymerization of MAN using di- $n$-hexylmagnesium in xylene at $25^{\circ} \mathrm{C}$.

reactions between the propagating carbanion and the cyano group. The formation of the hetero-structure caused by an attack of the propagating carbanion against the cyano group has been proposed by Erusallimsky et $a{ }^{4}{ }^{4}$ and by Ottolenghi and Zhilkha. ${ }^{7} \mathrm{We}$ can estimate the reactivity of the carbanion against the cyano group in $\mathrm{AN}$ or in PAN in comparison with that in MAN or in polymethacrylonitrile (PMAN) with experimental data on copolymerization results ${ }^{22}$ between $\mathrm{AN}$ and MAN, and of MO calculations for electron density and atomic bond population (ABP).

Figure 2 shows ${ }^{13} \mathrm{C}$ NMR spectrum for PMAN (sample AX-1) obtained using di- $n$ hexylmagnesium as an initiator in xylene at $25^{\circ} \mathrm{C}$. Although complicated splittings due to main chain configuration were observed for $\mathrm{CH}_{2}$ and $\mathrm{CH}_{3}$ carbon regions, ${ }^{23}$ no peak attributed to hetero-structure was found. This means that the propagating carbanion attacks the cyano group very rarely in this polymerization system.
Figure 3 illustrates the electron density of each atom, and Table II shows ABP values for $\mathrm{CN}, \mathrm{CC}$-vinyl, and $\alpha-\mathrm{CH}$ bonds, both obtained by ab-initio MO calculations based on STO-3G basis $\operatorname{set}^{15}$, for the principal bonds constituting AN, MAN, 2-cyanopropane (2-CP) as model compound for PAN chain and 2,2-dimethylpropanenitrile(2,2DMP) as model compound for PMAN chain. As far as electron densities and ABP values for the cyano group are concerned, little difference in the state of electron distribution for the cyano group was found between AN and MAN, or between 2-CP and 2,2-DMP. Kamide and Hisatani ${ }^{22}$ analyzed the ${ }^{13} \mathrm{C}$ NMR spectra of AN/MAN copolymers prepared using $n$-butylethylmagnesium as an initiator in xylene, and concluded that the AN monomer is incorporated more readily into the copolymer chain than is the MAN monomer. In other words, the reactivity of the vinyl double bond in $\mathrm{AN}$ is greater than that in MAN in anionic propagation. Provided that reactions between the propagating carba- 


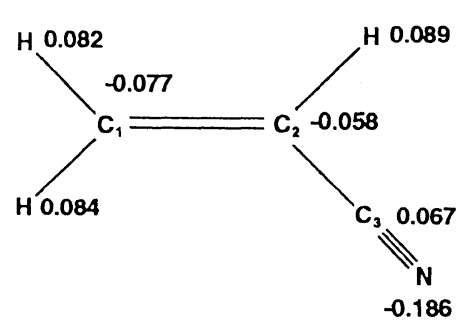

AN

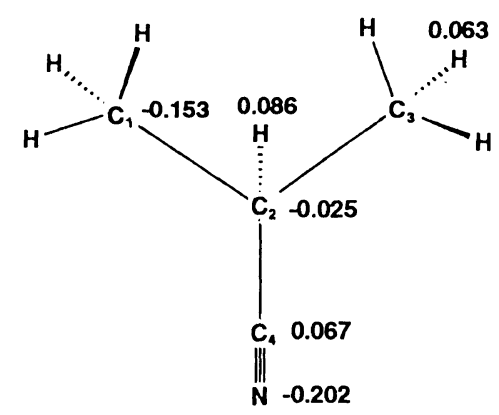

2-CP

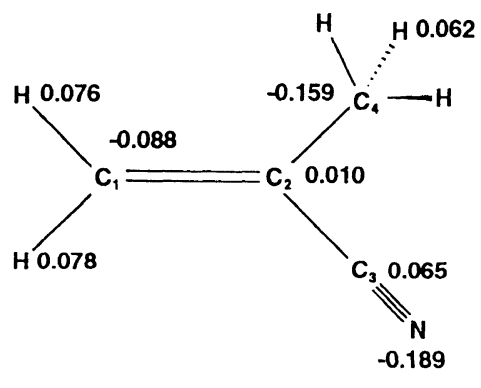

MAN

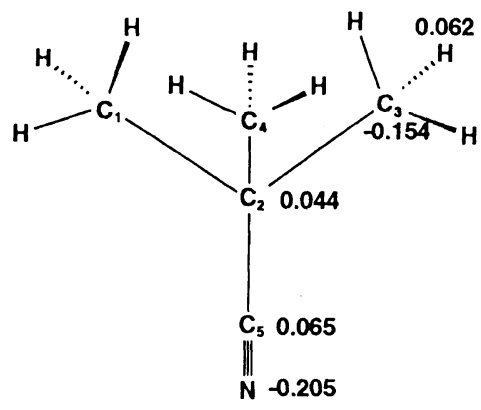

2,2-DMP

Figure 3. Electron densities of AN, MAN, 2-cyanopropane (2-CP) and 2,2-dimethylpropanenitrile (2,2-DMP) obtained by ab-initio calculation using the GAUSSIAN 88 program.

nion (PAN) ${ }^{-}$and the vinyl double bond in $\mathrm{AN}$ molecule the reactions between $\mathrm{PAN}^{-}$and the cyano groups of AN or PAN are competitive, we can consider, from comparison of the reactivity of these functional groups, that the former reactions occur with great superiority to the latter. So an attack of the propagating carbanion on the cyano group can be neglected for $\mathrm{AN}$ polymerizations.

In addition, if hetero-structures are formed by an attack of the carbanion on the cyano group, an imine-carbon peak ${ }^{7}$ or carbonylcarbon peak ${ }^{4,10}$ must be observed in ${ }^{13} \mathrm{C}$ NMR spectra. However, as shown in Figure 1, we cannot detect any peak in the imine-carbon area $(145-165 \mathrm{ppm})^{24}$ nor any peak at magnetic field lower than $170 \mathrm{ppm}$ which is characteristic of the carbonyl-carbon ${ }^{24}$ for an acetone-insoluble fraction (sample AM-1B). Even for an acetone-soluble fraction (sample AM-1C), which shows intense peaks in the ${ }^{13} \mathrm{C}$ NMR spectrum due to the heterostructures, imine-peaks cannot be observed. But for sample AM-1C, a small peak corresponding to carbonyl-carbon was observed. This may mean that the hydrolysis reaction of the cyano groups proposed by Erusallimsky et $a{ }^{4}{ }^{4}$ or the imine groups as suggested by Joh et al. ${ }^{10}$ occurs to a negligible extent. It can also be concluded that Michael additiontype decomposition (i), which leads to the formation of the imine structure seldom occurs.

The above results suggest that the predominant side reaction is not the attack of the carbanion on the cyano group, but on $\alpha$-proton 
in the AN monomer or in the PAN chain. Among elementary reactions (a) - (j), reaction (b) and (d) are those illustrating the abstraction of an $\alpha$-proton from the monomer, and reaction (f) that from the polymer chain. The abstraction of an $\alpha$-proton from the PAN chain by carbanions during the anionic polymerization of AN was also expected from observation of the epimerization reaction, which proceeds through the quarternary carbanion arising from the methine group of main chain, in PAN/DMSO solution in the presence of $n$-butyllithium. ${ }^{25}$

From MO calculations shown in Figure 3 and Table II it is clear that both the $\alpha$-proton of $\mathrm{AN}$ and that of the model compound representing the PAN chain, are relatively in electropositive state, and that electron density of the $\alpha$-proton in AN molecule is slightly less than that in backbone chain. Hence an

Table II. Atomic bond population (ABP) for primary chemical bonds of AN, MAN,

2-cyanopropane (2-CP), and 2,2-dimethylpropanenitrile (2,2-DMP) calculated by GAUSSIAN88 program using STO-3G basis set

\begin{tabular}{cccc}
\hline \multirow{3}{*}{ Molecule } & \multicolumn{3}{c}{$\mathrm{ABP}$} \\
\cline { 2 - 4 } & $P_{\mathrm{CN}}$ & $P_{\text {vinyl }}$ & $P_{\mathrm{c} \alpha-\mathrm{H} \alpha}$ \\
\hline AN & 1.4350 & 0.8315 & 0.7748 \\
MAN & 1.4348 & 1.1764 & - \\
2-CP & 1.4558 & - & 0.7615 \\
2,2-DMP & 1.4556 & - & - \\
\hline
\end{tabular}
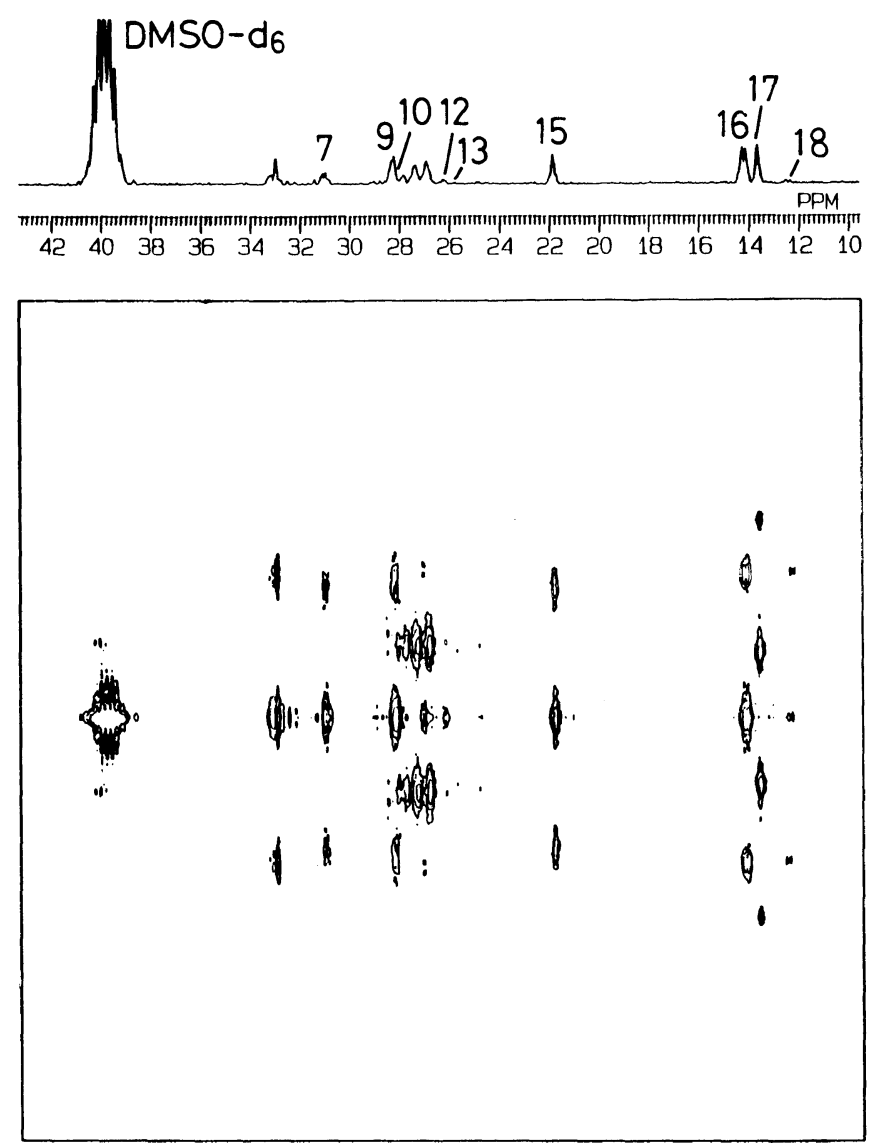

Figure 4. J-Resolved two dimentional ${ }^{13} \mathrm{C}$ NMR spectrum measured at $80^{\circ} \mathrm{C}$ for DMSO- $d_{6}$ solution of the acetone soluble fraction (sample AM-1C) initiated by di- $n$-hexylmagnesium in xylene at $25^{\circ} \mathrm{C}$. 
$\alpha$-proton in AN tends to be abstracted more easily by a carbanion. If an attack of propagating carbanion on a $\mathrm{n} \alpha$-proton in the monomer occurs frequently, and if the spieces newly produced propagates further, the following terminal structure is expected through reaction (b) or reaction $(\mathrm{d})$;<smiles>C#CC(C)CCC(C#N)CC1CC1</smiles>

The ${ }^{13} \mathrm{C}$ NMR resonances, originating from $s p^{2}$-carbon, aregenerally observed at low magnetic fields $(>110 \mathrm{ppm}) .{ }^{24}$ However, it was found from ${ }^{13} \mathrm{C}-{ }^{1} \mathrm{H} \mathrm{J}$ resolved 2D-NMR measurement that neither of the two ${ }^{13} \mathrm{C}$ nuclei at peaks 1 and 2, observed in magnetic field lower than $110 \mathrm{ppm}$, coupled to any ${ }^{1} \mathrm{H}$ nuclides. This means that 1 ) the possibility of the occurrence of reaction (h) is extremely low, and 2) the abstraction of an $\alpha$-proton from AN monomer (reaction (b) or (d)) does not occur, or even if it occurs, reaction products in reaction (b) or (d) no longer propagate to give compound (k). Summarizing, the peaks related to hetero-structure are due primarily to elementary reaction (f).

In anionic polymerizations involving polar monomers, in which the propagating species is an ion pair, Müller ${ }^{26}$ noticed that the complex formed between the metal cation and the polar group in the propagating chain brings about intramolecular attack of the carbanion (i.e., back-biting) as a side reaction. Berger et al. $^{5,9}$ suggest, on the basis of light scattering measurement of PAN samples prepared using alkoxide as an initiator, that an intramolecular abstraction reaction due to "backbiting" occurs to form short chain branching. It was also suggested that intermolecular attack of the carbanion on the PAN chain also happened, although less often, to form long chain branched structures. The intraand inter-molecular chain transfers to polymer are schematically represented as follows;
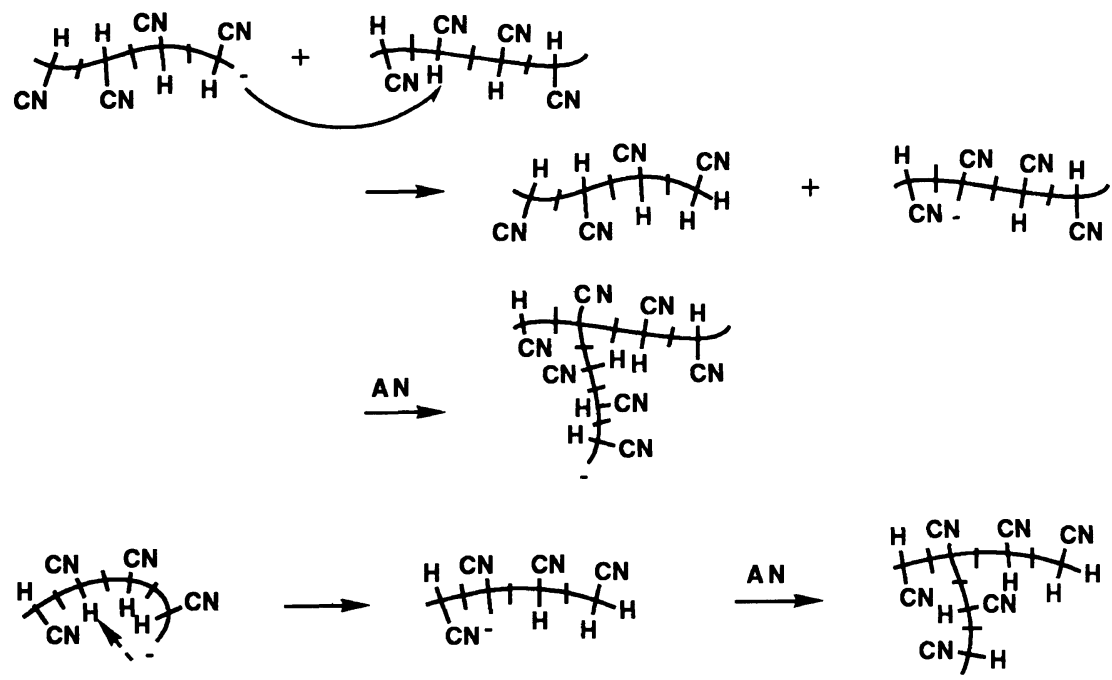

The precise nature of the transfer reaction $((\mathrm{l})$ or $(\mathrm{m}))$ which is dominant in the polymerization system will be discussed in section 2.2. It is concluded that main heterostructures existing in our samples are 1) the branching structure (n) formed by reaction (l) or (m) and 2) the end group (o) built by termination reactions such as reaction (d), although the extent to which these occur in the two samples (acetone-soluble fraction and 
-insoluble fraction) are different.
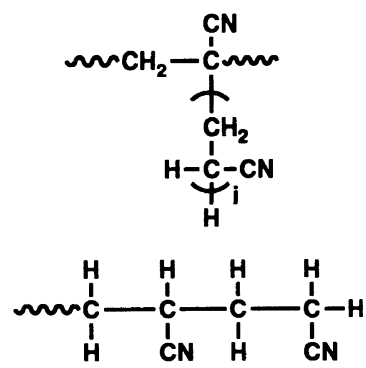

(o)

Assignment of NMR Spectra. ${ }^{13} \mathrm{C}-{ }^{1} \mathrm{H} \quad \mathrm{J}$ resolved 2D NMR spectra were first observed for the samples in order to determine which peak in ${ }^{13} \mathrm{C}$ NMR spectrum corresponds to methyl-, methylene-, or methine-carbon. Figure 4 shows the ${ }^{13} \mathrm{C}-{ }^{1} \mathrm{H} \mathrm{J}$ resolved 2D NMR spectrum for sample AM-1C, measured in $N, N^{\prime}$-dimethyl sulfoxide- $d_{6} \quad\left(\mathrm{DMSO}-d_{6}\right)$ at $80^{\circ} \mathrm{C}$. In the figure, the splittings from ${ }^{13} \mathrm{C}-{ }^{1} \mathrm{H}$ $\mathbf{J}$ coupling are observed in column axis, and (n) the number of splittings allows distinction between methyl-, methylene-, and methinecarbon (four, three, and two, respectively).

In Table III, the kind of groups (CN, methyl, methylene or methine group) corresponding to peaks $1-18$ are shown.

Figure 5 shows the ${ }^{13} \mathrm{C}-{ }^{1} \mathrm{H}$ COSY 2D-NMR spectrum for the acetone-insoluble fraction (sample AM-1B) in DMSO- $d_{6}$ at $80^{\circ} \mathrm{C}$. Here, we designate the seven peaks in the ${ }^{1} \mathrm{H}$ NMR spectra for sample AM-1B as peaks $1^{\prime}-6^{\prime}$ as shown in the Figure. Peaks $1^{\prime}$ and $4^{\prime}$ are observed for PAN prepared by radical po-

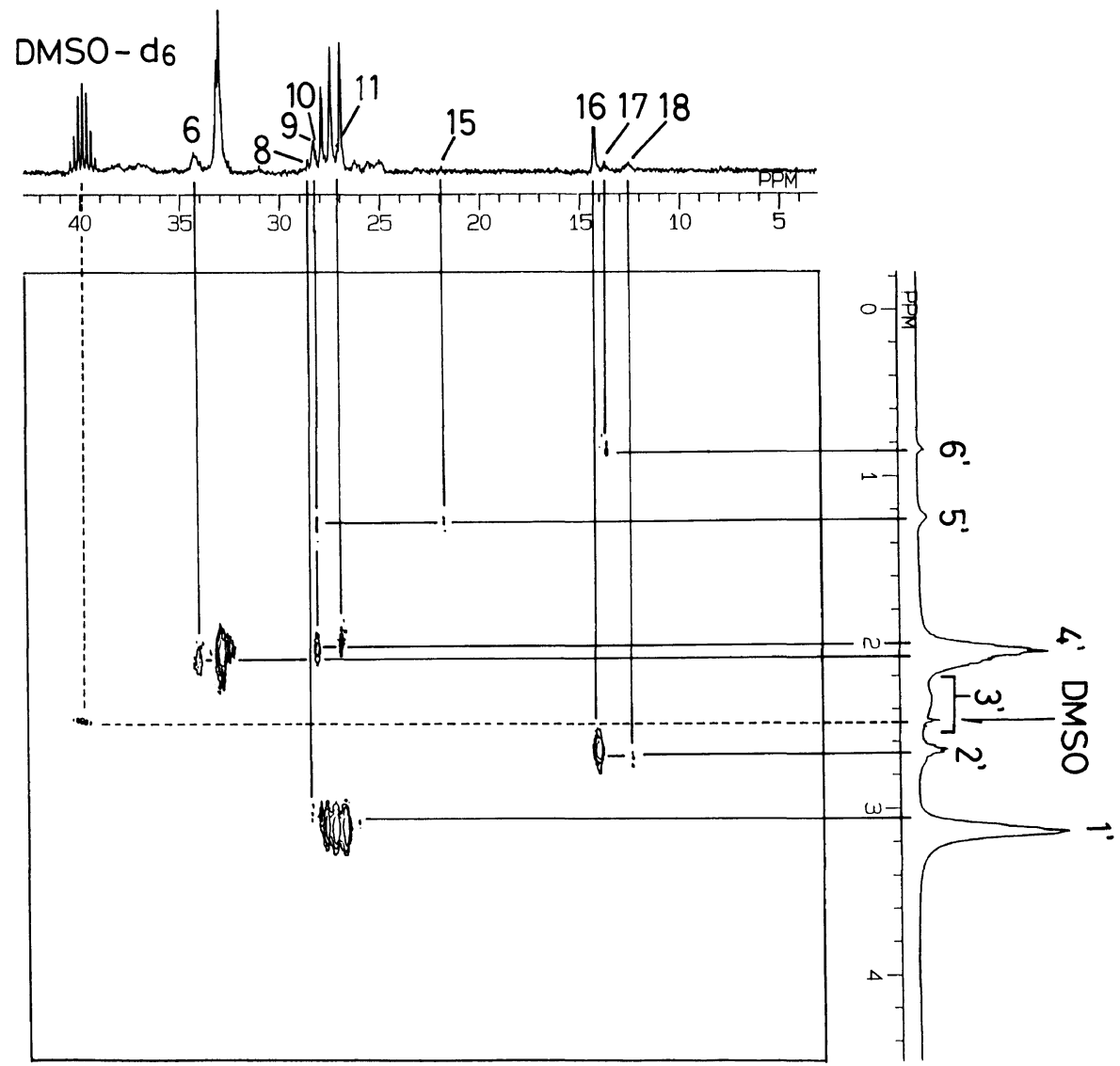

Figure 5. ${ }^{13} \mathrm{C}-{ }^{1} \mathrm{H}$ COSY spectrum measured at $80^{\circ} \mathrm{C}$ for DMSO- $d_{6}$ solution of the acetone-insoluble fraction (sample AM-1B) initiated by di- $n$-hexylmagnesium in xylene at $25^{\circ} \mathrm{C}$. 

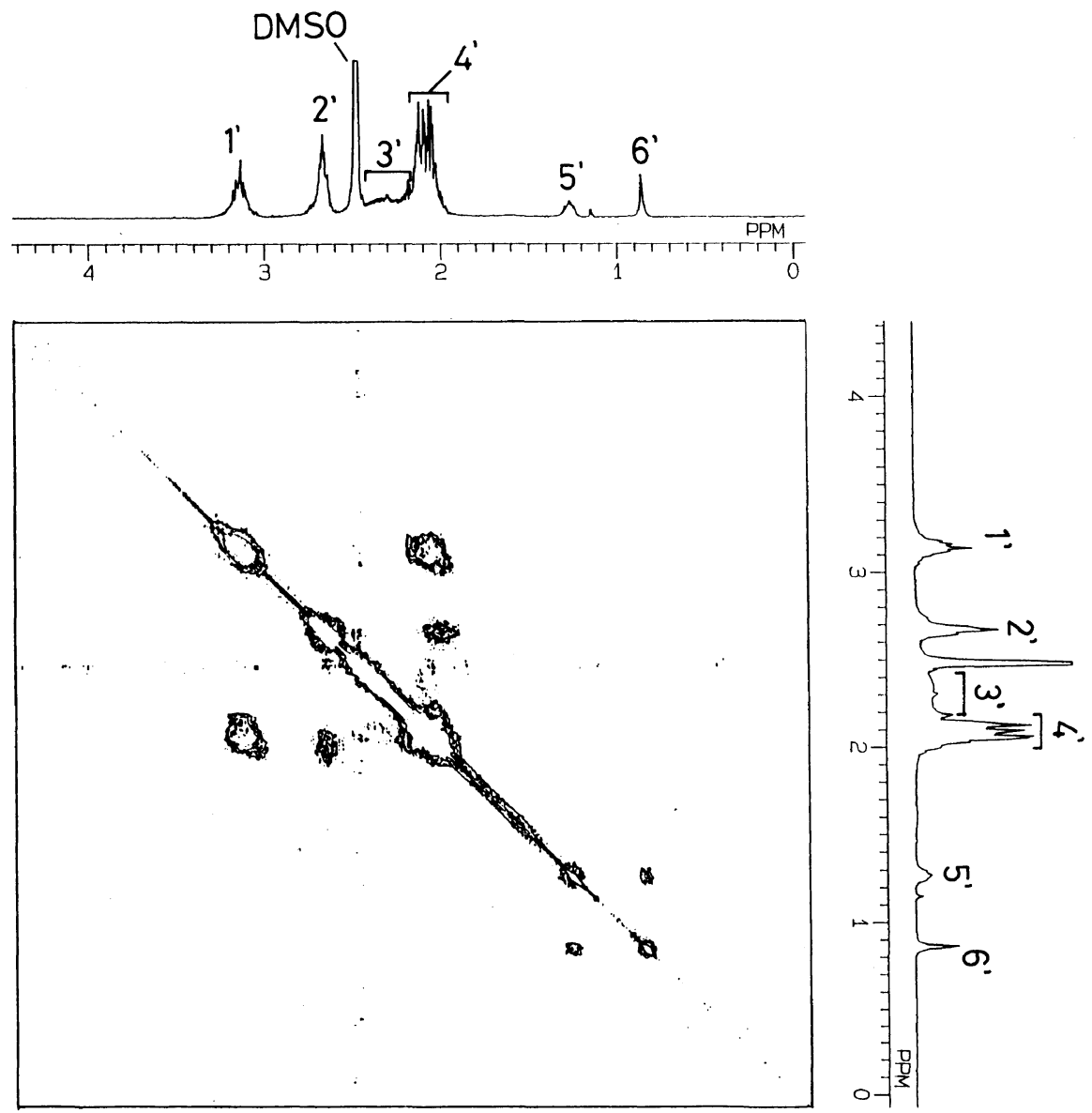

Figure 6. ${ }^{1} \mathrm{H}-{ }^{1} \mathrm{H}$ COSY spectrum measured at $80^{\circ} \mathrm{C}$ for DMSO- $d_{6}$ solution of the acetone-insoluble fraction (sample AM-1B) initiated by di- $n$-hexylmagnesium in xylene at $25^{\circ} \mathrm{C}$.

lymerization and assigned to methine-carbon and methylene-carbon in the chain backbone, respectively. Peaks 6, 9, and 11 in ${ }^{13} \mathrm{C}$ NMR spectrum, all assigned to methylene-carbon, have correlation with proton-peak $4^{\prime}$ in the main chain methylene region of ${ }^{1} \mathrm{H}$ NMR spectrum. The following correlations are observed: peak 9-peak $5^{\prime}$, peak 15-peak $5^{\prime}$, peak 16-peak $2^{\prime}$, peak 17-peak 6', peak 18-peak $2^{\prime}$. These results imply that peaks $9,15,16,18$ are related to methylene group having magnetic environments different from those of main chain methylene.

Figure 6 shows ${ }^{1} \mathrm{H}-{ }^{1} \mathrm{H}$ COSY 2D-NMR spectrum of the acetone-insoluble fraction (sample AM-1B) in DMSO- $d_{6}$ at $80^{\circ} \mathrm{C}$. Methylene proton peak $2^{\prime}$, which has not been observed for conventional PAN prepared by radial polymerization, was found to have vicinal coupling to proton in peak $4^{\prime}$, which has been assigned to the main chain methylene protons. Peaks $5^{\prime}$ and $6^{\prime}$ have also close correlation by vicinal coupling with each other, but do not correlate to resonances for the main chain methylene $\left(4^{\prime}\right)$ or methine $\left(1^{\prime}\right)$, showing that protons corresponding to peaks $5^{\prime}$ and $6^{\prime}$ have entirely different magnetic environments from those in the main chain.

As described before, significant dependence of the peak intensities on the nature of initiator 
Table III. Assignments for ${ }^{13} \mathrm{C}$ NMR peaks caused by side reactions for AM-1B/DMSO- $d_{6}$ solution at $80^{\circ} \mathrm{C}$

\begin{tabular}{|c|c|c|c|}
\hline Peak No. ${ }^{a}$ & $\begin{array}{l}\text { Chemical shift } \\
\quad(\mathrm{ppm})^{\mathrm{b}}\end{array}$ & $\begin{array}{l}\text { Kind of } \\
\text { group }^{c}\end{array}$ & Assignment $^{d}$ \\
\hline 1 & $120-121$ & $\mathrm{CN}$ & C* \\
\hline 2 & $118.8-119.2$ & $\mathrm{CN}$ & $\stackrel{*}{\mathrm{C}} \mathrm{N}$ \\
\hline 3 & $37.6-39.0$ & - & \\
\hline 4 & $36.1-37.6$ & - & $\delta^{\prime}, \zeta^{\prime}, \varepsilon^{\prime}$ \\
\hline 5 & $34.8-36.1$ & - & \\
\hline 6 & $33.7-34.8$ & $\mathrm{CH}_{2}$ & $\delta$ \\
\hline 7 & 31.0 & $\mathrm{CH}_{2}$ & $\gamma_{i}$ \\
\hline 8 & 28.6 & $\mathrm{CH}$ & $\varepsilon$ \\
\hline 9 & 28.3 & $\mathrm{CH}_{2}$ & $\delta_{i}, \eta_{i}$ \\
\hline 10 & 28.2 & $\mathrm{CH}$ & $\gamma$ \\
\hline 11 & 27.0 & $\mathrm{CH}_{2}$ & $\beta, \beta^{\prime}$ \\
\hline 12 & $25.8-26.6$ & $\mathrm{CH}$ & $\theta_{i}, \gamma^{\prime}$ \\
\hline 13 & $25.2-25.8$ & $\mathrm{CH}$ & $t^{\prime}$ \\
\hline 14 & $24.6-25.2$ & $\mathrm{CH}$ & $\eta^{\prime}$ \\
\hline 15 & 21.8 & $\mathrm{CH}_{2}$ & $\beta_{i}$ \\
\hline 16 & $14.1-14.4$ & $\mathrm{CH}_{2}$ & $\alpha$ \\
\hline 17 & 13.7 & $\mathrm{CH}_{3}$ & $\alpha_{i}$ \\
\hline 18 & $12.2-12.9$ & $\mathrm{CH}_{2}$ & $\alpha^{\prime}$ \\
\hline
\end{tabular}

a See Figure 1(a).

b TMS was used as an internal reference.

c Results confirmed by the ${ }^{13} \mathrm{C}-{ }^{1} \mathrm{H} \mathrm{J}$ resolved $2 \mathrm{D}$-NMR measurement.

d See formula (o)-(r) in the text.

indicates that peaks $7,9,12,15$, and 17 may mainly originate from formula $(p)$ formed in the initiation reaction (i.e., reaction (a)). Note that peak 12 is evidently doubly peaked: a sharp main peak is related to formula (p) and broad shoulder is due to the heterostructure formed by other side reactions (see formulae (o)-(r)).

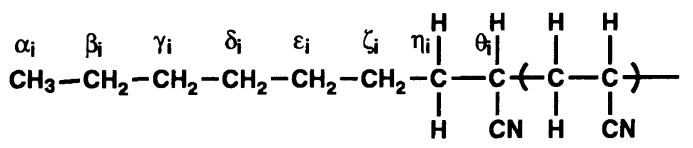

(p)

From ${ }^{13} \mathrm{C}-\mathrm{J}$ resolved 2D NMR measurements, peak 17 is assigned to the methyl-carbon (see Table III). Among all the possible chemical structures, including, of course, formula (p), formed in reactions (a) - (j), methyl group existed only in formula (p) and in $n$-hexane formed by reaction (b). The contamination of $n$-hexane in the reaction product is absolutely denied because all the samples were drid enough to evaporate any trace of $n$-hexane. Thus, peak 17 is assigned due to $\alpha_{i}$-carbon in formula (p).

The relationship between ${ }^{13} \mathrm{C}-{ }^{1} \mathrm{H}$ COSY (peak 17-peak 6', peak 9-peak $5^{\prime}$, peak 15peak $5^{\prime}$ ) and ${ }^{1} \mathrm{H}-{ }^{1} \mathrm{H}$ COSY (peak $5^{\prime}$-peak $6^{\prime}$ ) NMR spectra suggests an existance of the correlations between peak 17 and methylene peak (either peak 9 or 15). The chemical shift of $\beta$-carbon of $n$-hexane, as a model structure of the terminal portion of formula (p), was found at $23.1 \mathrm{ppm}$, which is approximately the same position (21.8 ppm) of peak 15 . Therefore, peak 15 is assigned based on the $\beta_{i^{-}}$ carbon.

Peak 9 may consist of a peak overlapping heavely two peaks, which are correlated with peaks $4^{\prime}$ and $5^{\prime}$ in ${ }^{1} \mathrm{H}$ NMR spectra, respectively (see Figure 5). The latter peak and peak 7 are assigned based on $\delta_{i^{-}}$and $\gamma_{i}$-carbons respectively, by a comparison of chemical shifts with those of $\delta$-carbon (29.7 ppm) of $n$-heptane and of $\gamma$-carbon (32.2 ppm) of $n$-hexane.

A sharp component consisting peak 12, relating to formula (p), is a methine-carbon. Formula (p) has only methine-carbon $\left(\theta_{i}\right.$ carbon) whose chemical shift may be much different from that of methine-carbon in main chain backbone. Then, a sharp component of peak 12 is assigned to $\theta_{i}$-carbon. In the same manner, a component of peak 9 relating to peak $4^{\prime}$ is assigned to $\eta_{i}$-carbon.

Peaks among peaks $1-18$ cannot be assigned to $\varepsilon_{i}$ - and $\zeta_{i}$-carbon, suggesting that these peaks heavily overlap with other larger peaks. Full assignments of peaks 7, 9, 12, 15, and 17 in ${ }^{13} \mathrm{C}$ NMR spectrum are summarized in the fourth column of Table III.

New ${ }^{13} \mathrm{C}$ NMR peaks other than these five peaks, that is, peaks $1-6,8,10,11,12-14$, 16 , and 18 , are considered therefore to originate from side reactions (d) or (f). Sheller et al. ${ }^{14}$ proposed the short branched structures $(n)$ with 
$i=1,2$ or 3 caused by reaction (m) (including in reaction (f)). If the structure with $i=1$ is formed, the propagating carbanion must abstract $\alpha$-proton from penultimate monomer unit, but in this case, it is very difficult for carbanion to attack $\alpha$-proton in penultimate monomer unit due to the poor degree of freedom for internal rotation. If only intramolecular chain transfer reaction occurs "selectively," the formation of a rigid intramolecular complex may be expected as an intermadiate state. In fact, the possibilities of the existence of intramolecular complexes during anionic polymerization have been demonstrated..$^{26,27}$ In the case of $i=2$, the propagating carbanion can form comparatively stable complex structure with the penpenultimate monomer unit. ${ }^{28)}$ Tsvetanov et al. ${ }^{29}$ indicated by means of semi-empirical MO calculation for a trimer model of polyacrylonitrile-anion with lithium counter ion that the metal cation was able to form chelate bonds with the cyano group of the penultimate unit, as well as with that of the penpenultimate unit. The "penultimate effect" has also been suggested in cases $^{21,30,31}$ other than $\mathrm{AN}$ polymerization. The probability of the "selective" formation of an intramolecular complex to form the structure corresponding to $i>2$ decreases drastically with increase in $i$. Therefore, we distinguish the branching structure with $i=2$, formed through an intramolecular complex, from those with $i>2$ which originates from an intra- or intermolecular chain transfer reaction. Assignments for the above fourteen ${ }^{13} \mathrm{C}$ NMR peaks were carried out for the following structures:

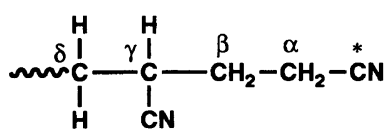

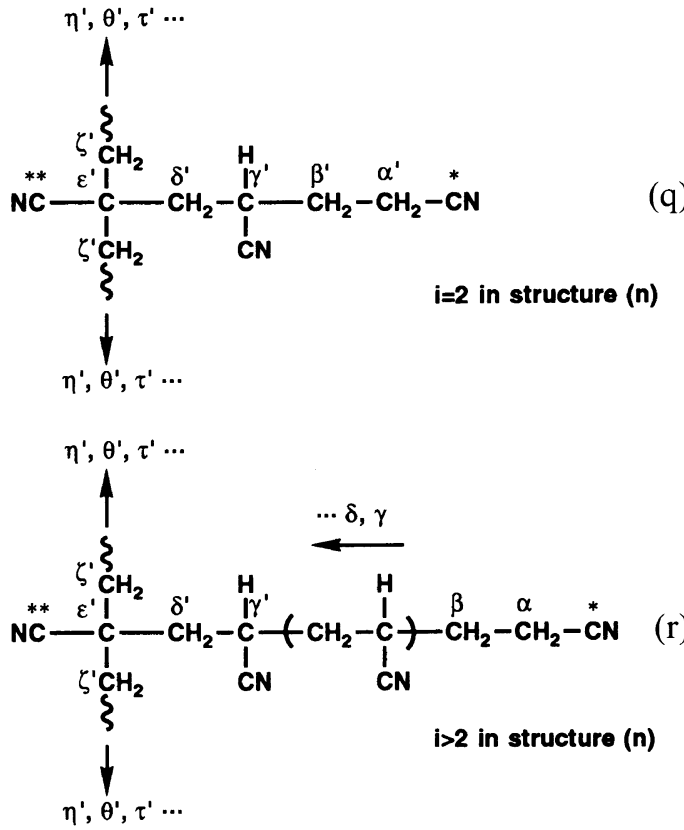

The chemical shift of peak 1 is larger by $1.2 \mathrm{ppm}$ than that of peak 2, and these two peaks are due to the cyano-carbon in hetero-structure. The ${ }^{13} \mathrm{C}$ nuclei of ${ }^{*} \mathrm{CN}$ (* means $\mathrm{CN}$ at the end of chain) and those of ** CN (**means $\mathrm{CN}$ bonding to quarternary carbon) in hetero-structures in the formulae (o), (q), and ( $r$ ) are in different magnetic environments from $\mathrm{CN}$ group in repeated units of linear PAN chains. The ${ }^{13} \mathrm{C}$ chemical shift of the $\mathrm{CN}$ group of glutaronitrile (a model compound of ${ }^{*} \mathrm{CN}$ ) and that for the cyanocarbon of PMAN, (a model compound of ${ }^{* *} \mathrm{CN}$ ) are observed at $119.3 \mathrm{ppm}$ and $c a$. $123.0 \mathrm{ppm}$ (see Figure 2) respectively. The former (119.3 ppm) is located at a higher magnetic field, and the latter $(123.0 \mathrm{ppm})$ appears at a lower magnetic field than that for the cyano groups for linear PAN (119.3120.3 ppm). Peak 1 in Figure 1(a) overlaps with the cyano peaks ( $c$ a. $120-121 \mathrm{ppm}$ ) of linear PAN, and peak 2 is located at $118.8-119.2$ ppm. From this, peak 1 can be attributed to ${ }^{* *} \mathrm{CN}$ carbon and peak 2 to ${ }^{*} \mathrm{CN}$ carbon. The validity of this assignment is also confirmed by the fact that local molecular motion of the 
carbon, located at nearer position to the end of a chain, is more active, resulting in longer relaxation time $T_{2}$ and sharpening of peak shape (i.e., peak 2 is sharper than peak 1). This is also observed for peaks corresponding to terminal group (peaks 7, 9, 12, 15, and 17) caused by the initiation reaction already assigned (see Figure 1(b)). As seen in Figure 1(a) and 1(b), peak 1 for the acetone-soluble fraction broadens more than that for the acetone-insoluble one because of the diversity of magnetic environment for ${ }^{*} \mathrm{CN}$ carbon.

From ${ }^{13} \mathrm{C}-{ }^{1} \mathrm{H}$ COSY measurement, both peaks 16 and 18 correlate to peak $2^{\prime}$. The chemical shifts of these peaks (i.e., $14.2 \mathrm{ppm}$ for peak 16, $12.4 \mathrm{ppm}$ for peak 18 , and $2.6-2.7 \mathrm{ppm}$ for peak $2^{\prime}$ ) nearly agree with those of $\alpha$-carbon peak for glutaronitrile (i.e., $15.2 \mathrm{ppm}$ for ${ }^{13} \mathrm{C}$ NMR resonance and 2.5-2.6 ppm for ${ }^{1} \mathrm{H}$ NMR). In addition, the sum of intensities for peak 16 and peak 18 coincides with that of peak 2 within error of measurement in the gated decoupling mode for each sample. From these, we can assign peaks 16 and 18 to $\alpha$ - and $\alpha^{\prime}$-carbon in formulae (o)-(r), respectively. Peak 18 is confirmed to broaden by several factors, for instance, the restriction in molecular motion caused by the position of $\alpha^{\prime}$-carbon nearby main chain backbone in comparison with that of $\alpha$-carbon situated in end of long chain, or the influence of configuration of main chain or neighbor branches.

Peak 16-carbon and peak 18-carbon, assigned to the $\alpha$-carbon and $\alpha^{\prime}$-carbon, respectively, are coupled with peak $2^{\prime}$-proton (Figure 5), connected to peak 4 '-proton through vicinal coupling (Figure 6). From Figure 5, it was found that carbons having a correlation with peak $4^{\prime}$ proton are peaks 6,9 , and 11 carbons, together with methylene carbon in the main chain. Therefore we can consider that one or two peaks among peaks 6,9 , and 11 correspond to $\beta$ - or $\beta^{\prime}$-carbon. Peak 9 should be excluded first because it is due to the end group formed by the initiation reaction and the chemical shift of $\beta$-carbon of glutaronitrile as model compound of $\beta$ - and $\beta^{\prime}$ carbons is found at $21.4 \mathrm{ppm}$. Then, peak 11 is speculatively attriuted to $\beta$ - and $\beta^{\prime}$ carbons. Methine peaks 8 and 10, observed in main chain methine carbon, can be assigned as in Table III by considering their intensities and chemical structures of $(0)-(r)$.

Methylene peak 6 is observed at $34 \mathrm{ppm}$, which is near that of the main chain methylene $(32.0-33.7 \mathrm{ppm})$, and its integral intensity is almost equivalent to that of peak 16. Peak 6 can therefore be assigned to the $\delta$-carbon of the chain end (o).

${ }^{13} \mathrm{C}-{ }^{1} \mathrm{H}$ J resolved 2D NMR spectra indicate that peaks 13, 14 together with a broad component of peak 12 are assigned to methine group of formulae (o)-(r). On the other hand, there are five methine groups in formulae (o) - (r) in which magnetic circumstances are different from the methine group belonging to the main chain: $\gamma, \varepsilon, \gamma^{\prime}, \eta^{\prime}$, and $\imath^{\prime}$-carbons. Peaks 8 and 10 are already assigned for $\varepsilon$ - and $\gamma$-carbons, respectively. Therefore, it can be considered that the above three peaks are assigned to either $\gamma^{\prime}$ - or $\eta^{\prime}$-carbon (or $l^{\prime}$-carbon). In addition, the intensity ratios of broad component of peaks 12, 13, and 14 are approximately $1: 2: 2$, showing that these three peaks may be assigned to $\gamma^{\prime}$-, $\imath^{\prime}$ - and $\eta^{\prime}$-carbons, resectively. $\delta^{\prime}-, \varepsilon^{\prime}$ - and $\zeta^{\prime}$-carbons will have their peaks at $35-41 \mathrm{ppm}$. $\zeta^{\prime}$ - and $\varepsilon^{\prime}$-carbons are considered to be in similar magnetic environments as the methylene carbons and tertiary carbons of PMAN (The chemical shifts of methylene carbon and tertiary carbon of PMAN are found at $46.7-49.8 \mathrm{ppm}$ and $32.1-33.1 \mathrm{ppm}$, respectively (Figure 2)).

The fourth column of Table III summarizes all new peak assignments in the ${ }^{13} \mathrm{C}$ NMR spectrum of sample AM-1B.

Structural Analysis of Reaction Product. On the basis of the assignments of ${ }^{13} \mathrm{C}$ NMR peaks in Table III, the number-average molecular weight $M_{n}$ and branching density were determined for the products prepared by 
anionic polymerization of $\mathrm{AN}$ using di- $n$ hexylmagnesium as an initiator. In this case, the ${ }^{13} \mathrm{C}$ NMR peak at $13.7 \mathrm{ppm}$ (peak 17 in Figure 1) was correlated to the initiator fragment incorporated into the polymer chain (i.e., $n$-hexyl group, molecular weight; 85). Therefore the apparent number-average degree of polymerization $P_{n}$ can be evaluated as the intensity ratio of the peak due to cyano carbon in the whole chain, $I_{\mathrm{CN}}$, to the peak $17, I_{17}$.

$$
\begin{aligned}
& M_{n, \mathrm{NMR}}=53 P_{n, \mathrm{NMR}}+86 \\
& P_{n, \mathrm{NMR}}=I_{\mathrm{CN}} / I_{17}
\end{aligned}
$$

Initiation efficiency $f$ is given by

$$
f=53 y\left[\mathrm{M}_{0}\right] / 2\left[\mathrm{C}_{0}\right] M_{n}
$$

where $y$ is conversion of $\mathrm{AN},\left[\mathrm{M}_{0}\right]$, initial monomer concentration, $\left[\mathrm{C}_{0}\right]$, initial initiator concentration.

Branched side chains were found to contain those corresponding to $i=2$ (see formula (q)). Then, the branching density, $D_{i=2}$, defined as the number of branching with $i=2$ existing per 100 repeating units, is given by

$$
D_{i=2}=100 I_{18} / I_{17} P_{\mathrm{n}}
$$

Here, $I_{18}$ is the intensity of pak 18 .

Peak 16 is due to the methylene carbon of the chain ends formed by termination reaction (formula (o)) and longer side chain ends (formula (r)). Here, we assume that 1) the number of active sites equals the resultant polymer chain number (i.e., we neglect the possibility of chain transfer to other molecules except polymer chain), and 2) the chain ends formed by termination reaction always have the chemical structure shown by formula (o). In this case, the number of initiating group in chain is equivalent to the number of terminating group in the chain. That is, the branching density, $D_{i>2}$, i.e., the number of branching side chains with $i>2$ (see formula (r)) per 100 repeating units is defined in a similar manner to that used for $D_{i>2}$.

$$
D_{i>2}=100\left(I_{16}-I_{17}\right) / I_{17} P_{\mathrm{n}}
$$

Here $I_{16}$ is the intensity of peak 16 .

$M_{n, \mathrm{NMR}}$ for acetone-solubles (sample AM-1C, $-2 \mathrm{C}$, and $-3 \mathrm{C}$ ) and acetone-insolubles (sample AM-1B, -2B, and -3B), estimated through eq 1 , are given in the third columns of Table IV.

\begin{tabular}{|c|c|c|c|c|c|c|c|c|c|}
\hline \multirow{2}{*}{ Sample code } & \multirow{2}{*}{$(\mathrm{mm})^{\mathrm{a}}$} & \multicolumn{3}{|c|}{ Molecular weight } & \multicolumn{2}{|c|}{ Branching density } & \multirow{2}{*}{$f$} & \multirow{2}{*}[\eta]{$^{\mathrm{d}} / \mathrm{g} \mathrm{ml}^{-1}$} & \multirow{2}{*}{$I_{\mathrm{CO}} / I_{\mathrm{CN}}$} \\
\hline & & $M_{n, \mathrm{NMR}}$ & $M_{n, \mathrm{VPO}}{ }^{\mathrm{b}}$ & $M_{v}^{\mathrm{c}}$ & $D_{i=2}$ & $D_{i>2}$ & & & \\
\hline \multicolumn{10}{|c|}{ (i) Acetone-soluble fractions } \\
\hline AM-1C & 0.39 & 505 & 550 & 530 & 3.4 & 0 & $0.41^{\mathrm{e}}$ & 6.6 & 0.02 \\
\hline AM-2C & 0.42 & 897 & 804 & 500 & 13.3 & 5.9 & $0.29^{\mathrm{e}}$ & 6.4 & 0.02 \\
\hline AM-3C & 0.43 & 330 & 605 & 430 & 2.0 & 0 & $0.17^{\mathrm{e}}$ & 5.8 & 0.18 \\
\hline \multicolumn{10}{|c|}{ (ii) Acetone-insoluble fractions } \\
\hline AM-1B & 0.35 & 5600 & - & 6000 & 2.7 & 5.7 & $0.05^{\mathrm{f}}$ & 28 & 0 \\
\hline AM-2B & 0.52 & 3400 & - & 14200 & 3.3 & 5.2 & $0.25^{\mathrm{f}}$ & 52 & 0 \\
\hline AM-3B & 0.53 & 2100 & - & 30200 & 1.8 & 0.3 & $0.12^{\mathrm{f}}$ & 81 & 0 \\
\hline
\end{tabular}
Note that three samples (AM-1, -2, and -3) employed here were prepared under rather

Table IV. Molecular characteristics of acetone-soluble and acetone-insoluble fractions of reaction products

a Triad isotacticity for chain backbone; estimated by ${ }^{13} \mathrm{C}$ NMR measurements.

b Measured in acetonitrile solution at $40^{\circ} \mathrm{C}$.

c Calculated from following Mark-Houwink-Sakurada equation for atactic PAN $\left.{ }^{18} ; \eta\right]=0.153 \times M_{v}^{-0.60}$

d Measured in dimethylsulfoxide solution at $25^{\circ} \mathrm{C}$.

e Values calculated using $M_{n, \mathrm{VPO}}$

f Values calculated using $M_{n, \mathrm{NMR}}$. 
extreme conditions (Table I). Values of $M_{n, \mathbf{V P O}}$, estimated by VPO, are in the fourth column of Table IV. Table IV contains also $D_{u=2}, D_{i>2}$ and $f$, evaluated using $M_{n, \text { vPO }}$ for the acetone-soluble samples and by $M_{n, \mathrm{NMR}}$ for the acetone-insoluble samples. For comparison, the limiting viscosity number $[\eta]$ and viscosityaverage molecular weight $M_{v}$ evaluated by Mark-Houwink-Sakurada equation for atactic PAN/DMSO solution at $25^{\circ} \mathrm{C}^{18}$ are in Table IV. Note that $M_{n, \mathrm{VPo}}$ is unquestionably more reliable than $M_{n \text {,NMR }}$ because the latter becomes valid only in the case where side reactions except reaction (d) and (f) may not occur. Acetone-soluble portions (sample AM-1C and AM-3C) are low molecular weight oligomers, which contain almost negligible amount of long chain branching $(i>2)$. For two samples, AM-1C and AM-2C the relation $M_{n, \mathrm{NMR}} \fallingdotseq$ $M_{n, \mathrm{VPO}}$ holds. On the other hand, $M_{n, \mathrm{NMR}}$ is significantly smaller than $M_{n, \mathrm{VPO}}$ in sample AM-3C, prepared under severe conditions (high polymerization temperature $\left(120^{\circ} \mathrm{C}\right)$ and low molar ratio of monomer / initiator $(\fallingdotseq 20))$ and in which the $\mathrm{CN}$ groups were confirmed, by the intensity ratio of the carbonyl carbon peak at $170-176 \mathrm{ppm}$ to that of the $\mathrm{CN}$ in ${ }^{13} \mathrm{C}$ NMR spectra $\left(I_{\mathrm{CO}} / I_{\mathrm{CN}}\right)$, to be partially ( $\fallingdotseq 20 \%$ ) converted to carbonyl groups (Table IV). This means that $M_{n, \mathrm{NMR}}$ has unavoidably large error for sample AM-3C because of the structural irregularity. Acetone-insolubles are evidently large molecular weight oligomers.

Figure 7(a) shows a GPC chromatogram of whole products (AM-1A) prepared with di- $n$-hexylmagnesium in xylene at $25^{\circ} \mathrm{C}$ and Figure 7(b), those for acetone-insolubles (AM-1B) and acetone-solubles (AM-1C). Acetone-insolubles and -solubles have apparently different molecular weight distributions. On comparison of three acetone-solubles, two samples, AM-1C and AM-3C, with low molecular weight have no $\left(D_{i>2}\right)$ and relatively few $\left(D_{i=2}\right)$ branching structures, but AM-2C with relatively high molecular weight contains some branches, i.e., the probability of occur-

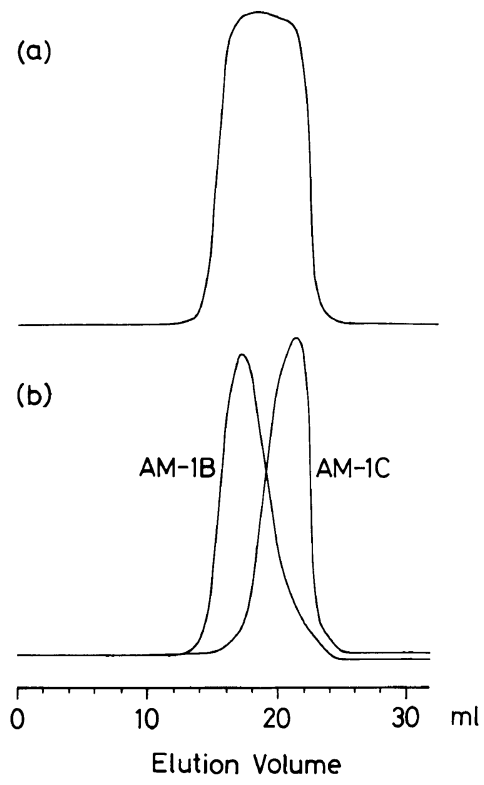

Figure 7. GPC chromatograms of (a) whole products (sample AM-1A) prepared using di- $n$-hexylmagnesium as an initiator in xylene at $25^{\circ} \mathrm{C}$, and of (b) the separated acetone-insoluble fraction (sample AM-1B) and acetonesoluble fraction (sample AM-1C) from sample AM-1A.

rence of the intramolecular chain transfer reaction to the polymer depends on chain length. For these results, two possibilities can be considered: One is that long chain branches with $i>2$ are mainly formed by intramolecular chain transfer reactions $(\mathrm{m})$, and another is that long chain branchs are formd by intermolecular chain transfer (1), i.e., a terminated chain by intermolecular chain transfer forms a low molecular weight fraction, and transfered anions grow into large particles to form a high molecular weight fraction. Table IV indicates that $f$ for producing acetone-soluble portion and that for producing acetone-insoluble portion are quite different: about $40 \%$ of initiators, which participated in the initiation reaction in xylene at $25^{\circ} \mathrm{C}$, contributes to the formation of acetone-soluble oligomers, and only $5 \%$ of initiators added is consumed in the formation of acetone-insoluble products. Krasnolskaya and Erusallimsky ${ }^{32}$ estimated $f$ to be $0.009-0.018$ from $M_{v}$ of the PAN 
obtained in hydrocarbon solvents using $n$ butyllithium or triisobutylmagnesiumiodide as an initiator at $-78^{\circ} \mathrm{C}--50^{\circ} \mathrm{C}$. Note that the polymerization temperature, $T_{\mathrm{p}}\left(25^{\circ} \mathrm{C}\right)$, used in sample AM-1B and AM-1C is 75 $100^{\circ} \mathrm{C}$ higher than those employed by Krasnolskaya and Erusallimsky. ${ }^{32}$

In contrast to this, $f$ for acetone-insolubles exceeds 0.1 when the polymers are synthesized at $120^{\circ} \mathrm{C}$. Previously, we observed ${ }^{33}$ that the stereospecific polymerization of $\mathrm{AN}$ proceeds using di- $n$-hexylmagnesium as an initiator in xylene at $T_{\mathrm{p}}>100^{\circ} \mathrm{C}$ (see the triad isotacticity (mm) in Table IV). The significance of the $T_{\mathrm{p}}$ dependence of $f$ means that the polymerization mechanism differs depending on $T_{\mathrm{p}}$. In the polymerization at $120^{\circ} \mathrm{C},(\mathrm{mm})$ values of acetone-solubles are clearly smaller than those of acetone-insolubles, supporting that two different propagating mechanisms.

${ }^{13} \mathrm{C}$ NMR peaks, assigned to short and long chain branchings, were also observed for polymers synthesized by anionic polymerization using initiators other than di- $n$-hexylmagnesium. ${ }^{13,33,34}$ The method empolyed here can also be used for polymerization, in which chain transfer to the molecule except polymer chain does not occur, and when the total number of polymer chains can be evaluated by any available method.

One major side reaction in AN polymerization reaction in xylene using di- $n$-hexylmagnesium is the chain transfer reaction to polymer. However, carbanion at the living end group itself is maintained as "living" when only side reaction ( $f$ ) occurs. Then, the termination reaction leading to "deactivation" of the active sites is expected to proceed by a different mechanism from the above side reaction. The high electrophilicity of the $\alpha$-proton in AN monomer, as evaluated by MO calculation and massive production of $n$-butane in the anionic polymerization of AN usin $n$-butyllithium in $n$-heptane, observed by Kawabata and Tsuruta, ${ }^{6}$ strongly suggest that the underlying mechanism of the termination reaction is the abstraction of the $\alpha$-proton from AN monomer, resulting in metalated compound, which does not participate in the propagation reaction and which will react with active protons, released by addition of the terminator, i.e., methanol and hydrochloric acid, to form AN monomer again.

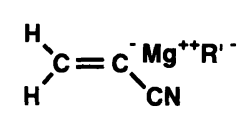

(s-i)

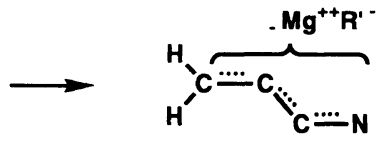

(s-ii)
The metalated compound (s) is supposed not to have the form of localized carbanion (s-i), but to exist in the form of carbanion, delocalized, by resonance stabilization between the vinyl group and cyano group (s-ii). This hypothesis, although not yet directly verified, may explain the dark yellowish coloring of the polymerization slurry.

The chain transfer reaction involving the $\alpha$-proton from AN monomer will proceed, as Kawabata and Tsuruta ${ }^{6}$ first suggested, even at the initiation stage (elementary reaction (b)) to bring about deactivation of initiator molecules. Under the polymerization conditions employed here (AM-1-AM-3), it is considered that $50-70 \%$ of the $\mathrm{C}-\mathrm{Mg}$ bonds are consumed in the side reaction which gives rise to the metalated $\mathrm{AN}$ monomer.

\section{CONCLUSIONS}

In the anionic polymerization of $\mathrm{AN}$ using di- $n$-hexylmagnesium as an initiator, the major side reactions are

(1) abstraction of an $\alpha$-proton from the monomer (a termination reaction) and

(2) abstraction of an $\alpha$-proton from the polymer chain (a chain transfer reaction), resulting in the compound as follows; 


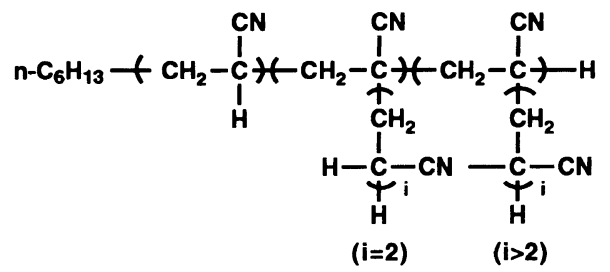

${ }^{13} \mathrm{C}$ NMR peaks for the products were assigned for the above structure.

Acknowledgement. The authors express their sincere gratitude to Prof. A. F. Johnson of Bradford University (UK) for his stimulating discussion.

\section{REFERENCES}

1. M. Fontanille, "Comprehensive Polymer Science," Vol. 3, G. C. Eastmond, A. Ledwith, S. Russo, and P. Sigwalt, Ed., Pergamon Press, Oxford, 1989, p 365.

2. A. H. E. Muller, "Comprehensive Polymer Science, Vol. 3, G. C. Eastmond, A. Ledwith, S. Russo, and P. Sigwalt, Ed., Pergamon Press, Oxford, 1989, p 401.

3. V. Dimonie, Makromol. Chem., 171, 93 (1973).

4. B. L. Erusallimsky, I. G. Krasnoselskaya, V. N. Krasulina, A. V. Novoselova, and E. V. Zashtserinsky, Eur. Polym. J., 6, 1391 (1970).

5. W. Berger and Hans-Jurgan Adler, Makromol. Chem., Macromol. Symp., 3, 301 (1986).

6. N. Kawabata and T. Tsuruta, Makromol. Chem., 98, 262 (1966).

7. A. Ottolenghi and A. Zhilkha, J. Polym. Sci., A1, 687 (1963).

8. M. Galin and J. C. Galin, J. Macromol. Sci. Phys., B11, 165 (1975).

9. G. Malsch, H. Dautzenberg, W. Kripper, D. Scheller, P. Fritzsche, and W. Berger, Acta Polym., 33, 626 (1982).

10. Y. Joh, Kobunshi, 24, 180 (1975).

11. N. S. Batty and J. T. Guthrie, Polymer, 19, 1145 (1978).

12. F. Severini and R. Gallo, Polym. Commun., 24, 350 (1983).

13. For example, see F. A. Bovey, Makromol. Chem., Macromol. Symp., 20/20, 105 (1988); K. Hatada, K. Ute, M. Kashiyama and M. Imanari, Polym. J., 22, 218 (1990); K. Hatada, K. Ute and M. Kashiyama, Polym. J., 22, 853 (1990); P. A. Lovell, T. H. Shah and F. Heatley, Polym. Commun., 32, 98 (1991).

14. D. Scheller, W. Kripper, G. Gro $\beta$ mann, and W. Berger, Acta Polym., 33, 632 (1982).

15. M. J. Frisch, M. Head-Gordon, H. B. Schlegel, K. Raghavachari, J. S. Binkley, C. Gonzalez, D. J.
Defrees, D. J. Fox, R. A. Whiteside, R. Seeger, C. F. Melius, J. Baker, R. L. Martin, L. R. Kahn, J. J. P. Stewart, E. M. Fluder, S. Topiol, and J. A. Pople, "Gaussian 88" (program), Gaussian, Inc., Pittsburgh, PA, 1988.

16. Y. Sasada, Ed., "Kagakubinran," 3rd ed, Maruzen Press, Tokyo, 1984, Chapter II (Molecular Structure and Crystal Structure), p 646.

17. K. Kamide, T. Terakawa, and H. Uchiki, Makromol. Chem., 177, 1447 (1976).

18. K. Kamide, H. Yamazaki, and Y. Miyazaki, Polym. J., 18, 819 (1986).

19. K. Kamide, H. Yamazaki, K. Okajima, and K. Hikichi, Polym. J., 17, 1233 (1985).

20. K. Kamide, H. Yamazaki, K. Okajima, and K. Hikichi, Polym. J., 17, 1291 (1985).

21. C. B. Tsuetanov and D. T. Docheva, J. Polym. Sci., $A$, 14, 2253 (1986).

22. K. Kamide and K. Hisatani, Polym. J., 24, 1377 (1992).

23. Y. Inoue, K. Koyama, R. Chujo, and A. Nishioka, J. Polym. Sci. Polym. Lett. Ed., 20, 547 (1972).

24. E. Breitmaier and W. Voelter, "Carbon-13 NMR Spectroscopy," 3rd, ed, VCH, New York, 1987, p 119.

25. H. Ono, K. Hisatani, and K. Kamide, unpublished results. We found that isotactic PAN, prepared by $\gamma$-ray irradiation on $\mathrm{AN}$-urea canal complex, readily epimerized into almost atactic configuration in DMSO solution in the presence of $n$-butyllithium at $80^{\circ} \mathrm{C}$; recently, other study supporting the occurrence of epimerization reaction for atactic PAN was published by Z. Bashir, G. Manns, D. M. Service, D. C. Bott, I. R. Herbert, R. N. Ibbett, and S. P. Church, Polymer, 32, 1826 (1991).

26. A. H. E. Müller, "Recent Advances in Anionic Polymerization," T. E. Hogen-Esch and J. Smid, Ed., Elsevier, New York, N. Y., 1987, p 205; A. H. E. Müller, "Comprehensive Polymer Science," Vol. 3, G. C. Eastmond, A. Ledwith, S. Russo, and P. Sigwalt, Ed., Pergamon Press, Oxford, 1989, p 406.

27. B. L. Erusallimsky, "Mechanisms of Ionic Polymerization," Consultants Bureau, New York, N. Y., 1986, p 80.

28. The description is supported by some circumstances; i.e., in the polymerization of ethylene, it was confirmed by ${ }^{13} \mathrm{C}$ NMR analysis [D. J. Cutler, P. J. Hendra, M. E. A. Cudby, and H. A. Willis, Polymer, 18, 1005 (1977)] that, propagating free radical attacked on the penpenultimate unit to form $n$-butyl side chain as intermediate state, and similar type "back-biting" to this $n$-butyl group led to the formation of ethyl side chain. Such "back-biting" is also reported in other cases for radical polymerization [C. Anthony Barson, "Comprehensive Polymer Science," Vol. 3, G. C. Eastmond, A. Ledwith, S. Russo, and P. Sigwalt, Ed., Pergamon Press, Oxford, 
Side Reactions in Anionic Polymerization of AN

1989, p 181]; these data show that, even if rigid intermediate complexes are not formed, $\alpha$-carbon in propagating chain easily interacts with $\alpha$-proton in penpenultimate unit because of the conformational circumstance essentially.

29. C. B. Tsuetanov, D. T. Docheva, D. K. Dinov, E. B. Petrova, and I. M. Panayotov, "Recent Advances of Anionic Polymerization," T. E. Hogen-Esch and J. Smid, Ed., Elsevier, New York, 1987, p 155.

30. B. L. Erusallimsky, "Mechanisms of Ionic Polym- erization," Consultants Bureau, New York, 1986, p 197.

31. A. Soum and M. Fontanille, Makromol. Chem., 183, 1145 (1982).

32. I. G. Krasnolskaya and B. L. Erusallimsky, Polym. Sci. USSR, 25, 2285 (1983).

33. K. Kamide, H. Ono, and K. Hisatani, Polym. J., 24, 917 (1992).

34. V. R. Pai Verneker, and B. Shaha, Macromolecules, 19, 1851 (1986). 